Phase Error and Associated Cross-Polarization Effects In Cassegrainian-Fed Microwave Antennas

\author{
W. V. T. Rusch
}
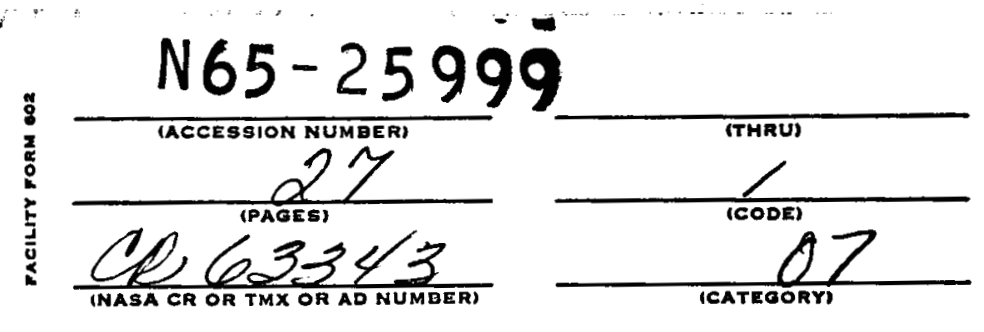

GPO PRICE $\$$ OTS PRICE(S) \$

Hard copy (HC)

Microfiche (MF)
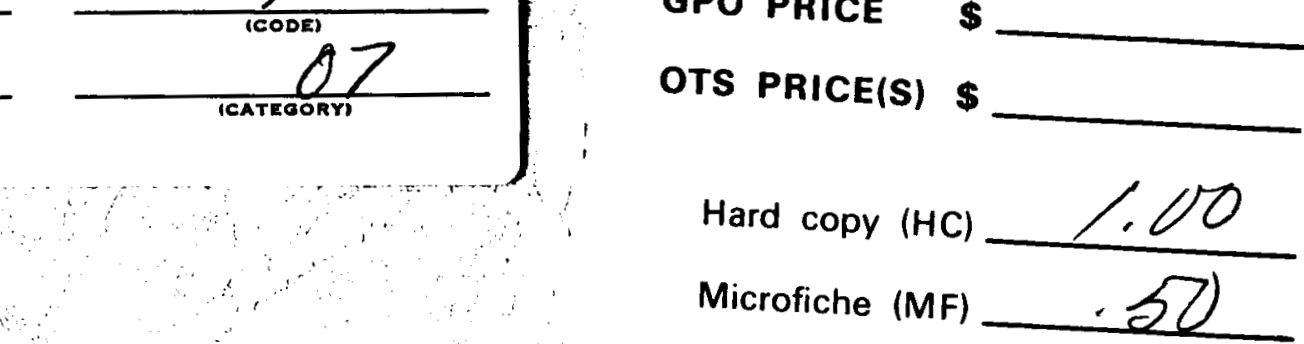

-

-32)

JET PROPULSION LABORATORY

CALIFORNIA INSTITUTE OF TECHNOLOGY

PASADENA, CALIFORNIA 
Technical Report No. 32-610

\section{Phase Error and Associated Cross-Polarization Effects In Cassegrainian-Fed Microwave Antennas}

W. V. T. Rusch

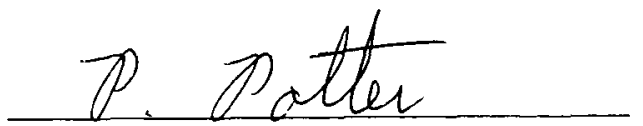

P. Potter, Manager

Communications Elements Research

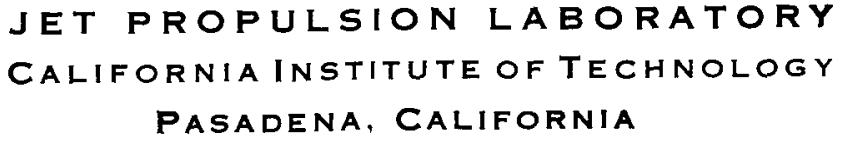

May 30,1964 


$$
\begin{gathered}
\text { Copyright (C) } 1965 \\
\text { Jet Propulsion Laboratory } \\
\text { California Institute of Technology }
\end{gathered}
$$

Prepared Under Contract No. NAS 7-100 National Aeronautics \& Space Administration 


\section{CONTENTS}

\section{Introduction}

II. Fields Scattered from the Subdish . . . . . . . . . . . . . 3

III. Calculation of Phase Characteristics . . . . . . . . . . . . . . 6

A. Variation of Phase Characteristics with Taper of Subdish Illumination . . . . . . . . . . . . . . . . . . . 6

B. Variation of Phase Characteristics with Feed-Horn Position and Subdish Shape . . . . . . . . . . . . . . . 8

C. Variation of Phase Characteristics with Paraboloid F/D . . . . 10

D. Phase Characteristics for Illumination by Circular $\mathrm{TE}_{11}$-Mode Horn . . . . . . . . . . . . . . . . . 12

E. Phase Characteristics for Twice the Frequency . . . . . . . 13

F. Phase Characteristics for Minimum-Blocking Condition . . . . 13

IV. Fields Reflected from the Paraboloid . . . . . . . . . 15

V. Calculation of Gain Characteristics . . . . . . . . . . . $\quad$. 17
A. Variation of Gain Characteristics with Taper of Subdish Illumination . . . . . . . . . . . . . . . . . 17
B. Variation of Gain Characteristics with Feed-Horn Position and Subdish Shape . . . . . . . . . . . . . . . 18
C. Variation of Gain Characteristics with Paraboloid F/D . . . . . 18
D. Gain Characteristics for Illumination by Circular $\mathrm{TE}_{11}$-Mode Horn . . . . . . . . . . . . . . . 18
E. Gain Characteristics for Twice the Frequency . . . . . . . 19
F. Gain Characteristics for Minimum-Blocking Condition . . . . . 19
G. Feed-System Misalignment . . . . . . . . . . . . . . 19

VI. Summary of Results and Conclusions . . . . . . . . . . 20

References . . . . . . . . . . . . . . . . . . . 21

\section{FIGURES}

1. Cassegrainian antenna . . . . . . . . . . . . . . . . 2

2. Geometry of hyperboloidal reflector . . . . . . . . . . . 3

3. Amplitude of field scattered from subdish . . . . . . . . . 3

4. Best-fit E-plane phase lag for various ranges of angle . . . . . . . . 4

5. Phase-center characteristics for various ranges of angle . . . . . . 4 


\section{FIGURES (Cont'd)}

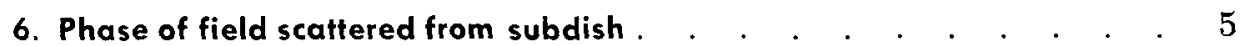

7. Geometry 1 . . . . . . . . . . . . . . . . . 7

8. E-plane phase lag for geometry 1, variable feed-horn taper . . . . 8

9. Phase-center characteristics for geometry 1 , variable feed-horn taper . . . . . . . . . . . . . . . . . . . . . 8

10. Geometries 1,2 , and 3 showing variable subreflector shape and variable feed-horn phase center . . . . . . . . . . . . . . . . 9

11. E-plane phase lag for geometries 1, 2, and 3 (9-db feed-horn taper).

12. Phase-center characteristics for geometries 1,2 , and 3 (9-db feed-horn taper)

13. Geometries 1,4 , and 5 showing variable F/D

14. E-plane phase lag for geometries 1,4 , and 5 (9-db feed-horn taper)

15. Phase-center characteristics for geometries 1,4 , and 5 (9-db feed-horn taper)

16. Comparison of phase lag for geometry 1 with $T E_{11}$-mode and dual-mode excitation

17. Comparison of phase-center characteristics for geometry 1 with $T E_{11}$-mode and dual-mode excitation .

18. Comparison of E-plane phase lag for geometry 1 (double frequency) and geometry 1 (original frequency)

19. Comparison of phase-center characteristics for geometry 1 (double frequency) geometry 1 (original frequency)

20. Geometry for minimum-blocking condition (9-db feed-horn taper) . . 14

21. Comparison of E-plane phase lag for minimum-blocking condition and geometry 1 (9-db feed-horn taper)

22. Comparison of phase-center characteristics for minimum-blocking condition and geometry 1 (9-db feed-horn taper)

23. Paraboloid geometry

24. Aperture contours of cross-polarized field (geometry 1 , 9-db feed-horn taper).

25. Gain characteristics for geometry 1 , variable feed-horn taper

26. Gain characteristics for geometries 1, 2, and 3 19-db feed-horn taperl.

27. Gain characteristics for geometries 1,4 , and 5 (9-db feed-horn taper) 


\section{FIGURES (Cont'd)}

28. Comparison of gain characteristics for geometry 1 with $\mathrm{TE}_{11}$-mode and dual-mode excitation . . . . . . . . . . . . . . 18

29. Comparison of gain characteristics for geometry 1 (double frequency) and geometry 1 (original frequency) . . . . . . . . . . . . . . . . 19

30. Comparison of gain characteristics for minimum-blocking condition and geometry 1 (9-db feed-horn taper) . . . . . . . . . . 19

31. Gain and cross-polarization for geometry 1, 13-db feed-horn taper, with phase shift introduced between $\mathbf{E}$ - and $\boldsymbol{H}$-plane . . . . . 19

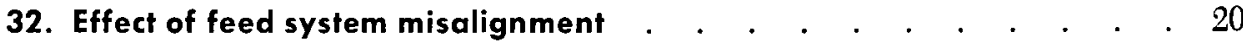




\section{ABSTRACT}

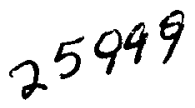

Phase error in the aperture field of a microwave paraboloidal antenna degrades antenna gain in two ways: the asynchronism of partial field contributions arriving at an axial field point reduces the magnitude of the total field there, and the phase error may generate a crosspolarized component of the aperture field that further reduces the axial gain. Because of phase ripples in the field reflected from the subdish, a Cassegrainian-fed antenna may be considerably more susceptible to phase-error effects than conventional focal-point-fed antennas. Consequently, a two-part analysis was carried out to evaluate the importance of these phase-error effects in Cassegrainian systems. The feed-system fields were computed and a best-fit phase center was found. Then the axial gain was computed in terms of the feed-system fields. An expression for the phase-error loss was defined to evaluate the effects of diffractive phase ripple, feed-system misalignment, etc. Numerical analyses were carried out for a wide range of antenna parameters. It was concluded that for a 19-wavelength subdish and a nearly symmetrical phase and amplitude feed pattern the loss in axial gain due to diffractive phase error may be only a small fraction of a decibel.

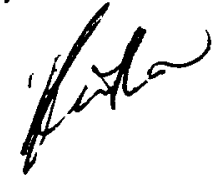

\section{INTRODUCTION}

Cassegrainian optics, because of numerous radiofrequency and mechanical advantages, are frequently employed in the design of feed systems for microwave antennas. Low-noise antennas for space communication (Ref. 1), monopulse antennas for tracking applications (Ref. 2), antennas for radio and radar astronomy (Refs. 3 and 4) and antennas with conical scan capability are examples of advantageous application of the Cassegrainian principle to microwave-antenna feed systems.

The basic operation of a Cassegrainian feed system for a microwave antenna can be described by the meth- ods of geometrical ray optics (Fig. 1). In the transmit mode, a spherical wave emerging from the phase center of the primary feed is transformed by the hyperboloidal subreflector into a spherical wave emerging from the focus of the paraboloid; this wave is then reflected from the paraboloid and radiated into space as a plane wave. Every ray emerging from the primary feed and undergoing reflections at the two surfaces will travel an equal distance to the plane of the aperture, thus producing a perfectly in-phase aperture field. In the receive mode, the sequence of reflections and wave transformations is reversed, but the basic principles of operation are the same. 
A quantitative application of ray optics may be used to calculate the amplitude and polarization transformations that take place upon reflection from the subdish. Such calculations have been used with considerable success in the determination of overall antenna gain, certain types of cross-polarization losses, etc. (Ref. 5). However, the techniques of geometrical optics may not be used to describe various diffraction effects that may play important roles in the determination of antenna performance. Such an effect is the aperture phase error due to phase ripples in the wave reflected from the subdish. This report is intended to extend the application of vector diffraction theory in order to determine the significance of additional diffraction effects in causing possible deterioration of axial gain in Cassegrainianfed microwave antennas. In particular, the axial-gain loss due to aperture phase error and associated crosspolarization will be considered.

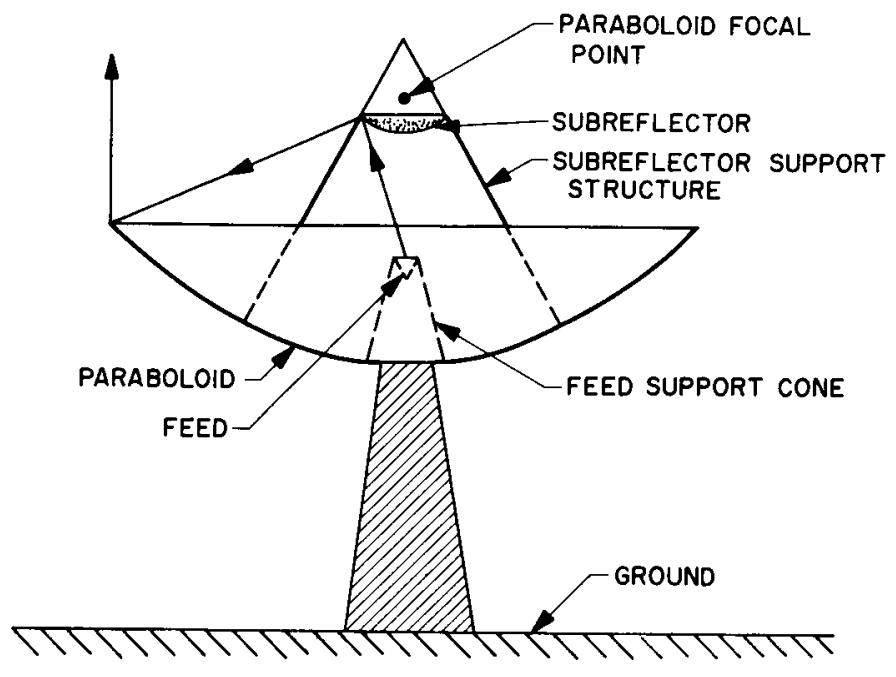

Fig. 1. Cassegrainian antenna 


\section{FIELDS SCATTERED FROM THE SUBDISH}

The geometry (in cross-section) of a Cassegrainian feed system is shown in Fig. 2. It consists of a pointsource illuminator or feed horn and of a hyperboloidal subdish. The phase center of the illuminator coincides with one of the two hyperboloid foci. By using the surface-current integration method of vector diffraction theory (Refs. 6 and 7), it is possible to derive expressions for the field scattered from the subdish. These fields are indicated in Eq. 1:

$$
\begin{aligned}
\bar{E}_{s}= & \frac{e^{i k R}}{R}\left\{\sum_{m}\left[f_{m}(\theta) \sin m_{\phi}+g_{m}(\theta) \cos m_{\phi}\right] \bar{a}_{o}\right. \\
& \left.+\sum_{m}\left[h_{m}(\theta) \sin m_{\phi}+k_{m}(\theta) \cos m_{\phi}\right] \bar{a}_{\phi}\right\}
\end{aligned}
$$

where $\bar{a}_{\theta}$ and $\bar{a}_{\phi}$ are the polar and azimuthal unit vectors, respectively, and $f_{m}(\theta), g_{m}(\theta), h_{m}(\theta), k_{m}(\theta)$ are polar functions involving integrations of the illuminator fields, various phase factors, and the hyperboloidal geometry. It should be noted that these fields are centered at $O$, the feed-horn phase center, and not at $F$, the secondary focus of the hyperboloid.

A recent development in the field of Cassegrainian feed systems has been the use of a dual-mode, smallflare conical feed horn as the illuminator (Ref. 8). This dual-mode horn has a nearly rotationally symmetric beam and suppressed sidelobes. Furthermore, extremely precise analytical expressions for the amplitude and phase of the dual-mode horn fields are available. Consequently, in the analysis that follows, the primary feed

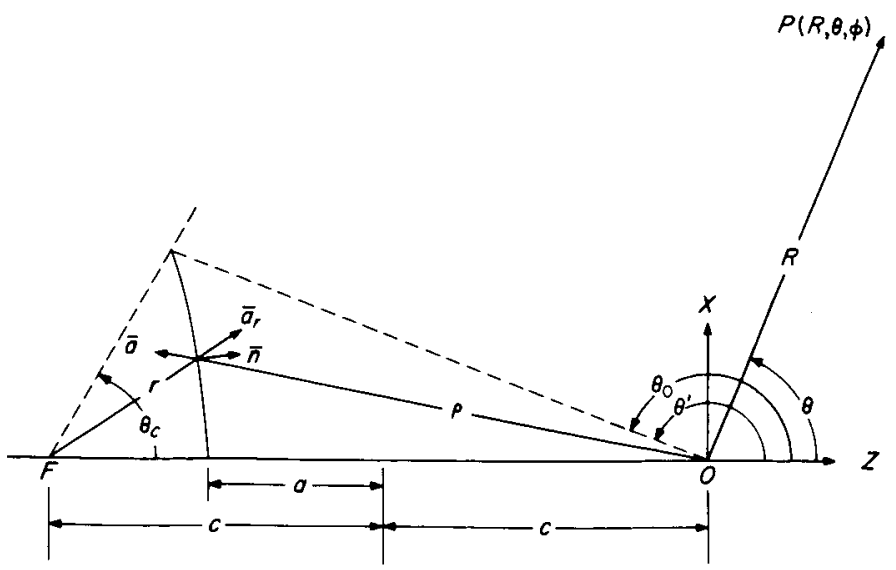

Fig. 2. Geometry of hyperboloidal reflector shall be assumed to be such a dual-mode horn. Although the subsequent numerical results will strictly apply only to dual-mode horn applications, many of these results can be generalized to other types of primary illumination.

Incorporation of the dual-mode illuminator fields into Eq. 1 yields Eq. 2:

$$
\bar{E}_{\kappa / d m}=\frac{e^{i k n}}{R}\left\{f_{1}(\theta) \sin \phi a_{\theta}+k_{1}(\theta) \cos \phi \bar{a}_{\phi}\right\}
$$

where $f_{1}(\theta)$ and $k_{1}(\theta)$ are the $E$-plane and $H$-plane patterns of the field scattered from a subdish illuminated by a dual-mode horn. These calculated patterns are plotted in Fig. 3 with the corresponding experimental patterns. The hyperboloidal geometry is such as to illuminate a paraboloid with a semi-diameter of $60 \mathrm{deg}$, as viewed from the focus; $e=1.5146, D / \lambda=19.5, c / \lambda=23.165$. Agreement between theory and experiment is seen to be good. The deep nulls in the experimental patterns are caused by feed-horn blockage.

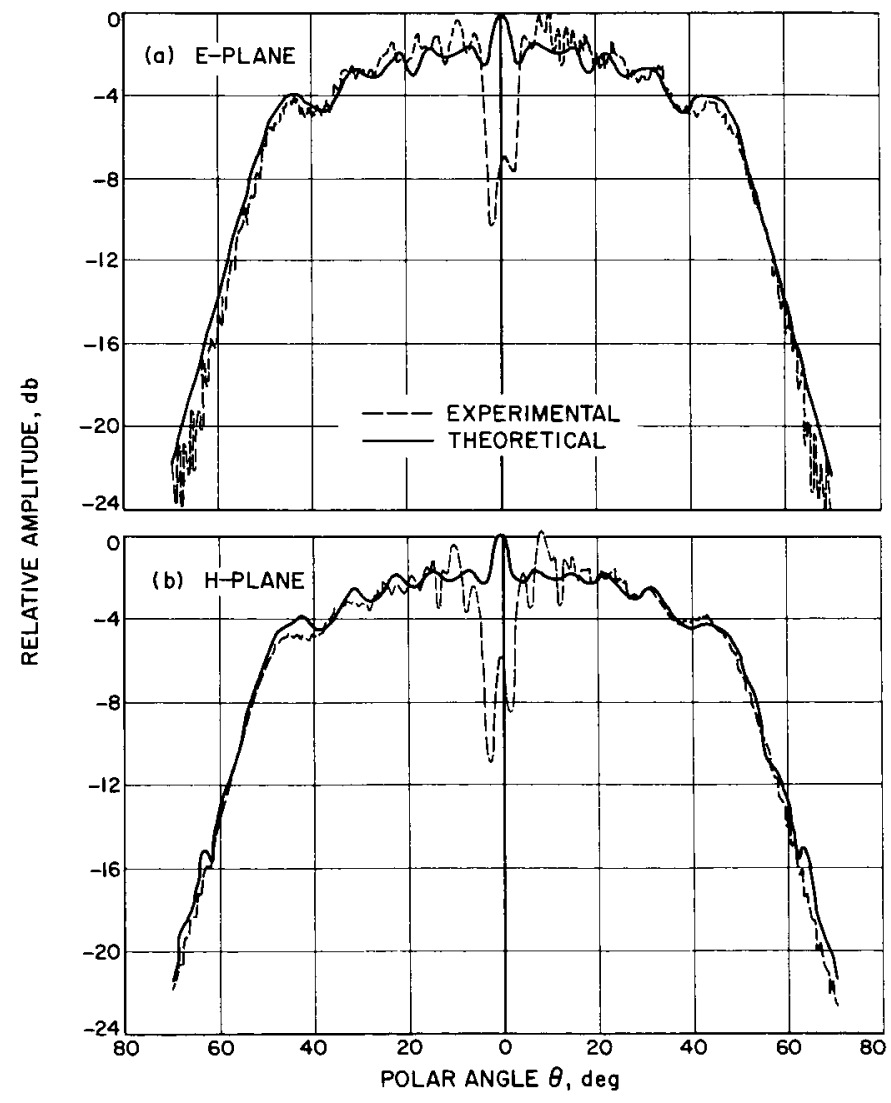

Fig. 3. Amplitude of field scattered from sublish 

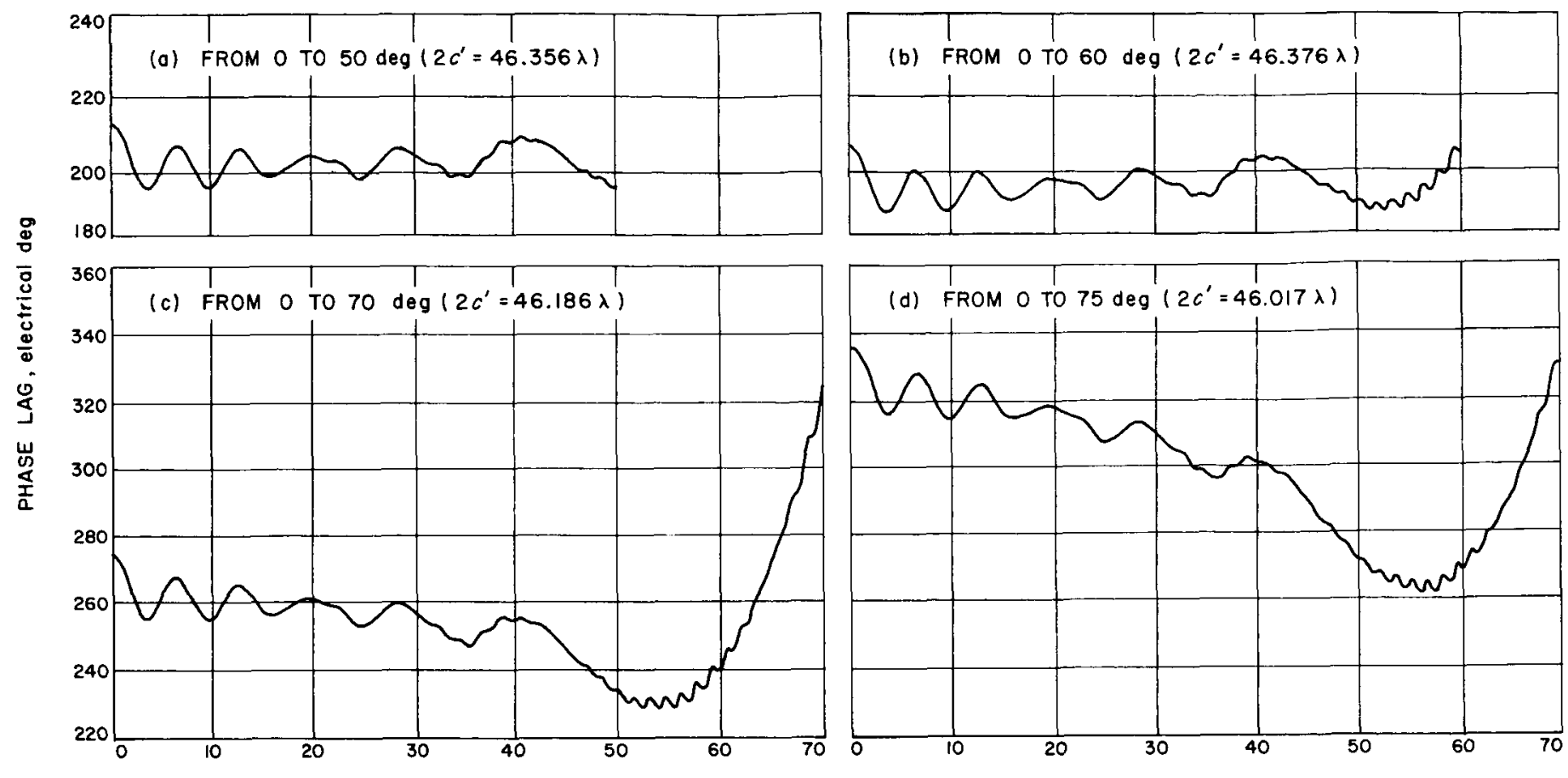

Fig. 4. Best-fit $E$-plane phase lag for various ranges of angle le $=1.5146, D / \lambda=19.5, c / \lambda=23.165$, dual-mode horn feed, 9-db taper, 60-deg edge anglel

In the limit of vanishing wavelength, the scattered field would have constant phase on a sphere centered at the subdish focus, which is also the geometrical-optics phase center. Because the wavelength is non-vanishing, and because the subdish is truncated, the center of a constantphase sphere will generally not coincide with the geometrical-optics phase center. In fact, a constant-phase surface of purely spherical shape will not, in general, exist. Consequently, the phase center of the scattered field will be defined as the center of a best-fit spherical cap over which the rms phase deviation is minimum. Because of a severely monotonically increasing phase lag at wide angles, the best-fit phase center is a function of the angular size of the spherical cap.

Such phase centers were calculated in the $E$ - and $H$-planes for the scattered field considered in the amplitude comparisons shown in Fig. 3. Different phase centers are calculated by minimizing the rms deviations over spherical caps of varying sizes. The results are indicated in Fig. 4. Choice of the various phase centers produces different phase distributions on the corresponding quasiconstant-phase spherical cap. The sharp, wide-angle increase of phase deviation is evident in parts (c) and (d) of Fig. 4. Since the subdish was designed to illuminate a 60-deg paraboloid, the phase increase beyond $60 \mathrm{deg}$ should not cause serious deterioration of gain.

The numerical results of the calculations for the four different cap sizes are tabulated in Fig. 5. $\Delta_{F i}$ is the difference (in wavelengths) between the $E$-plane and geometrical-optics phase centers; $\Delta_{H i}$ is the difference between the $H$-planc and geometrical-optics phase center; $\Delta_{E H}$ is the difference between the $E$ - and $H$-phase centers. The inherent computer accuracy has been estimated to be $\pm 0.0015 \lambda$. It is evident that there is a

\begin{tabular}{|c|c|c|c|c|c|}
\hline & E-PLANE PC & H-PLANE PC & $\Delta_{E G}$ & $\Delta_{H G}$ & $\Delta_{E H}$ \\
\hline $\begin{array}{c}\text { GEOMETRY OF } \\
\text { OPTICS }\end{array}$ & 46.330 & 46.330 & 0 & 0 & 0 \\
\hline $0-75 \mathrm{deg}$ & 46.017 & 45.997 & 0.313 & 0.332 & 0.019 \\
\hline $0-70 \mathrm{deg}$ & 46.186 & 46.162 & 0.144 & 0.168 & 0.024 \\
\hline $0-60 \mathrm{deg}$ & 46.376 & 46.356 & 0.046 & 0.026 & 0.020 \\
\hline $0-50 \mathrm{deg}$ & 46.356 & 46.348 & 0.026 & 0.018 & 0.008 \\
\hline NOTE: 2C'IS TABULATED FOR EACH PHASE CENTER (PC) IN TERMS OF WAVE- \\
LENGTHS $(\lambda)$
\end{tabular}

Fig. 5. Phase-center characteristics for various ranges of angle le $=1.5146, D / \lambda=19.5, c / \lambda=23.165$, dual-mode horn feed, 9-db taper, 60-deg edge angle) 
difference between (1) the calculated and geometricaloptics phase centers, and (2) the $E$ - and $H$-plane phase centers. Furthermore the location of the phase center is dependent on the size of the spherical cap over which the minimum phase deviation is sought.

One would intuitively expect that, for the example being considered, the best-fit phase center for a 60-deg spherical cap would produce optimum antenna performance, since this much of the scattered field is intercepted by the paraboloid. The theoretical phase patterns for such a best-fit 60 -deg cap are compared with the corresponding experimental results in Fig. 6. A serrodyne test setup was used to measure the phase patterns (Ref. 9). The experimental patterns have a spike at $\theta=0$ from horn blockage. Otherwise, the agreement is relatively good, particularly with regard to the peak-to-peak phase ripple and the number of ripples. The seven relatively small phase ripples from 0 to $60 \mathrm{deg}$ are distributed over an aperture radius of approximately 100 wavelengths. The small size and number of the ripples serve to justify the plane-wave reflection formulas used in Section IV to determine the paraboloid surface currents.

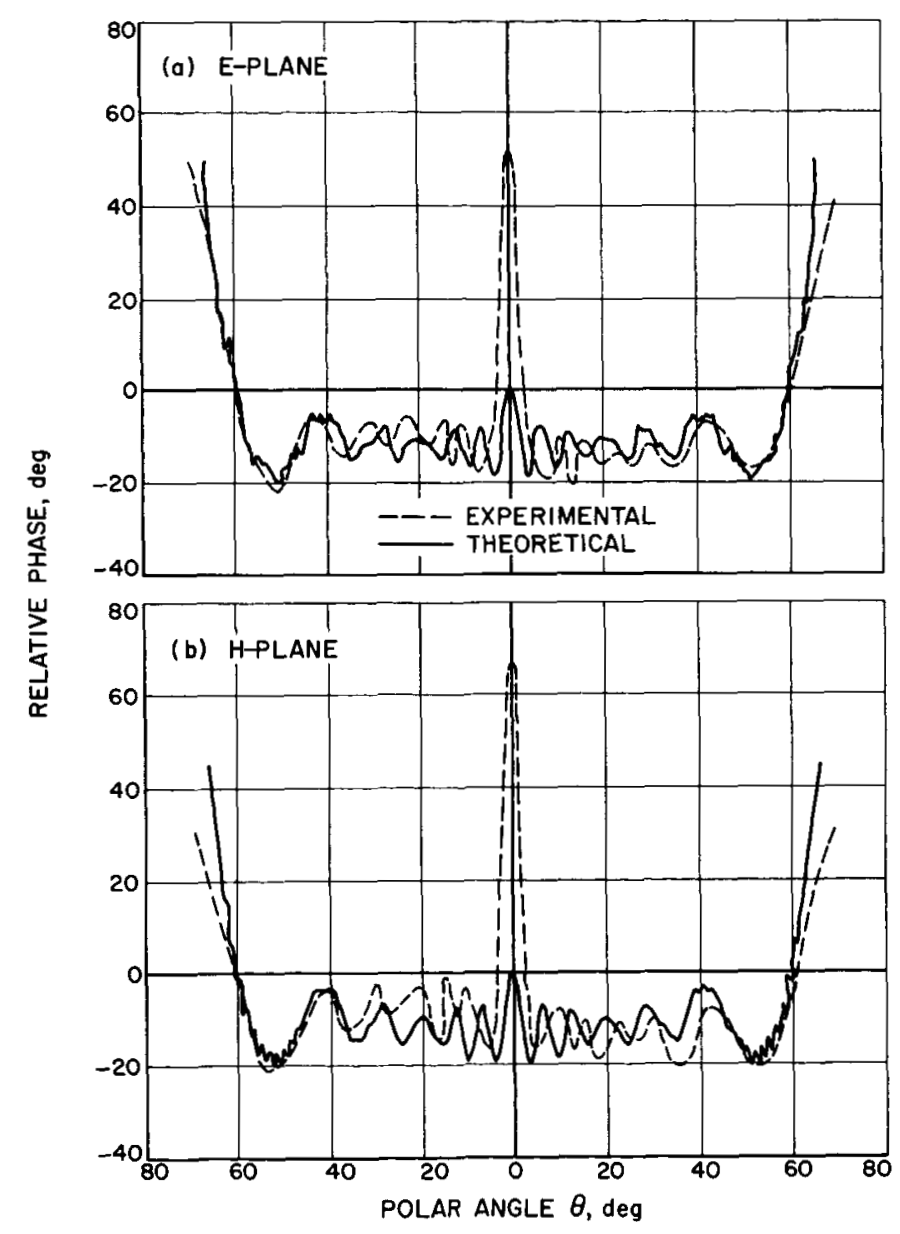

Fig. 6. Phase of field scattered from subdish 


\section{CALCULATION OF PHASE CHARACTERISTICS}

Numerous interrelated factors affect the performance of a Cassegrainian feed system. Among these are the subdish size and shape, the location of the illuminator, the feed-horn illumination taper, and the paraboloid focal length/diameter (F/D).

The subdish size determines both the amount of aperture blocking and the integrated spillover beyond the edge of the paraboloid. The subdish shape (i.e., the eccentricity of the hyperboloid), determines the so-called magnification factor of the antenna (Ref. 10), which plays an important role in cross-polarization losses (Ref. 5).

Location of the feed-horn illuminator is indirectly related to the subdish shape; i.e., the closer the horn is to the subdish, the flatter the subdish becomes. Frequently, for mechanical and RF convenience, the feed horn is placed at the vertex of the paraboloid. In all the cases considered in this Report, however, the horn will be located at an intermediate position, which allows a greater overall horn length and which is consistent with the unique Jet Propulsion Laboratory (JPL) removable RF cone assembly (Ref. 1). ${ }^{1}$

The taper of the feed-horn illumination at the edge of the subreflector determines both the paraboloid aperture illumination taper, which affects axial gain, and the amount of forward spillover beyond the edge of the subdish, which may cause high near-in sidelobes. This taper is determined by the length of the horn and the size of its aperture.

The effects of paraboloid F/D (or angular semidiameter) on gain, sidelobes, cross-polarization, etc., have been investigated and reported in the literature for many years. The F/D has several direct and indirect effects on feed-system design, not the least of which is the length of the support structure.

In the analysis to follow, the phase characteristics of the system will be investigated as these parameters are varied. With one exception, however, the diameters of both the principal paraboloidal reflector and the secondary hyperboloidal reflector will remain constant.

1 This removable cone configuration as first proposed by Mr. Peter Foldes of the RCA Victor Co., Montreal, Canada.

\section{A. Variation of Phase Characteristics with Taper of Subdish Illumination}

Figure 7 illustrates Geometry 1:

Paraboloid

Diameter

201.67 wavelength

Focal length

Angular semidiameter (at focus)

87.33 wavelength

$60 \mathrm{deg}$

Hyperboloid

Diameter

Secondary focus

Angular semidiameter (at horn)

Eccentricity

Magnification

All the geometrical parameters remain constant with the exception of the radius of the feed-horn aperture which is varied in such a way as to produce $3-, 9-, 13-$, and $18-\mathrm{db}$ tapers at the subdish edge."

Figure 8 shows the resulting phase plots for the four illumination tapers. Clearly, an increase in taper results in a decrease in the peak-to-peak phase excursion. This effect is consistent with the interpretation that tapering the illumination has decreased the importance of the portion of the infinite hyperboloid that has been omitted. Consequently, the diffraction effects from truncating the subdish are reduced in magnitude.

Figure 9 contains a tabulation of the phase characteristics as the taper is varied. In general, an increase in taper brings the $E$-and $H$-plane phase centers closer to the geometrical-optic phase center, although with a slight increase in the separation between the $E$ - and $H$-plane phase centers. The seperations are at most 0.082 wavelength (or about 30 electrical degrees). In addition, the peak-to-peak phase error decreases from 0.059 wavelength $(21 \mathrm{deg})$ to 0.014 wavelength $(15 \mathrm{deg})$.

\footnotetext{
"Not including "space-loss."
} 


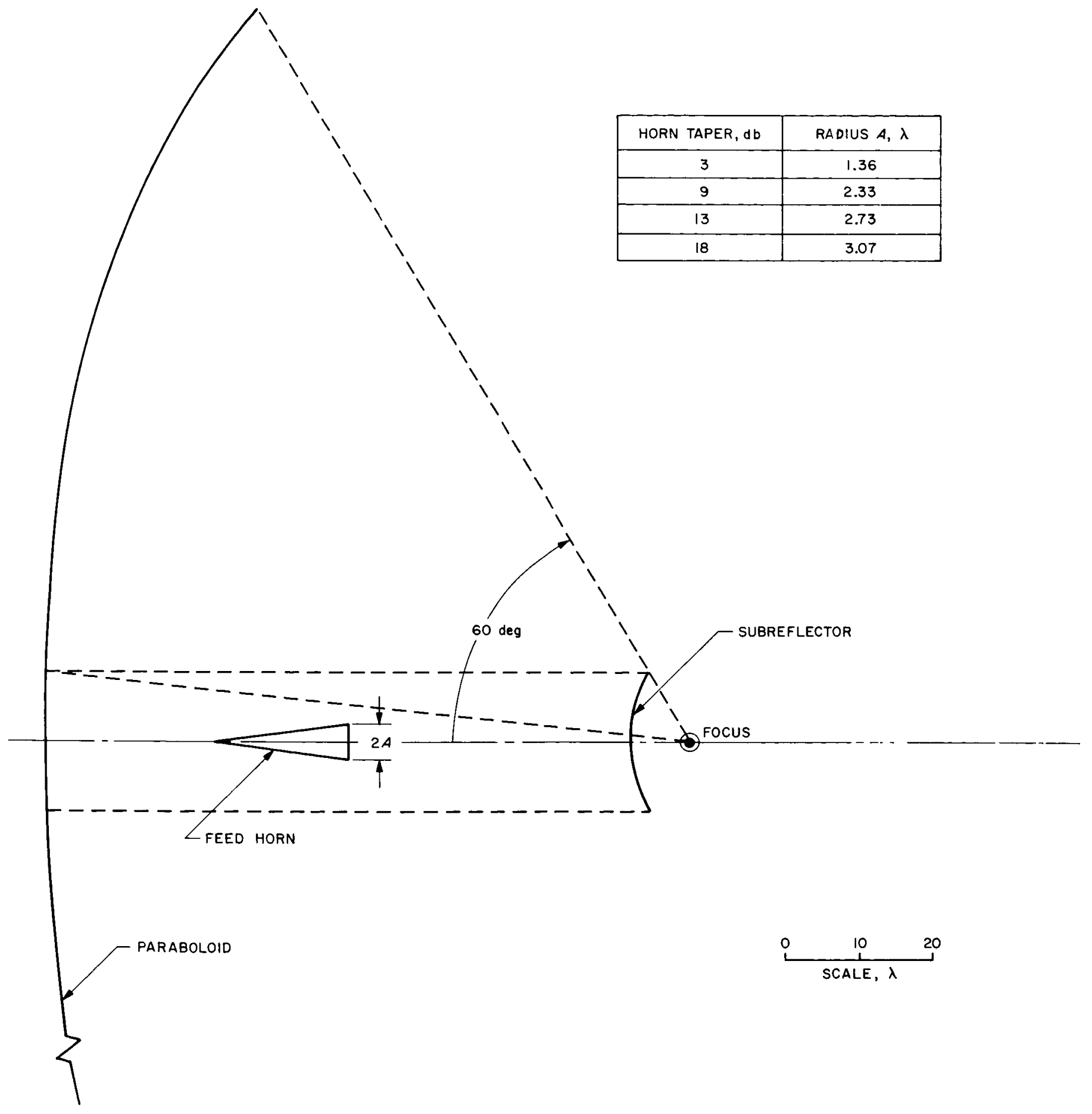

Fig. 7. Geometry 1 


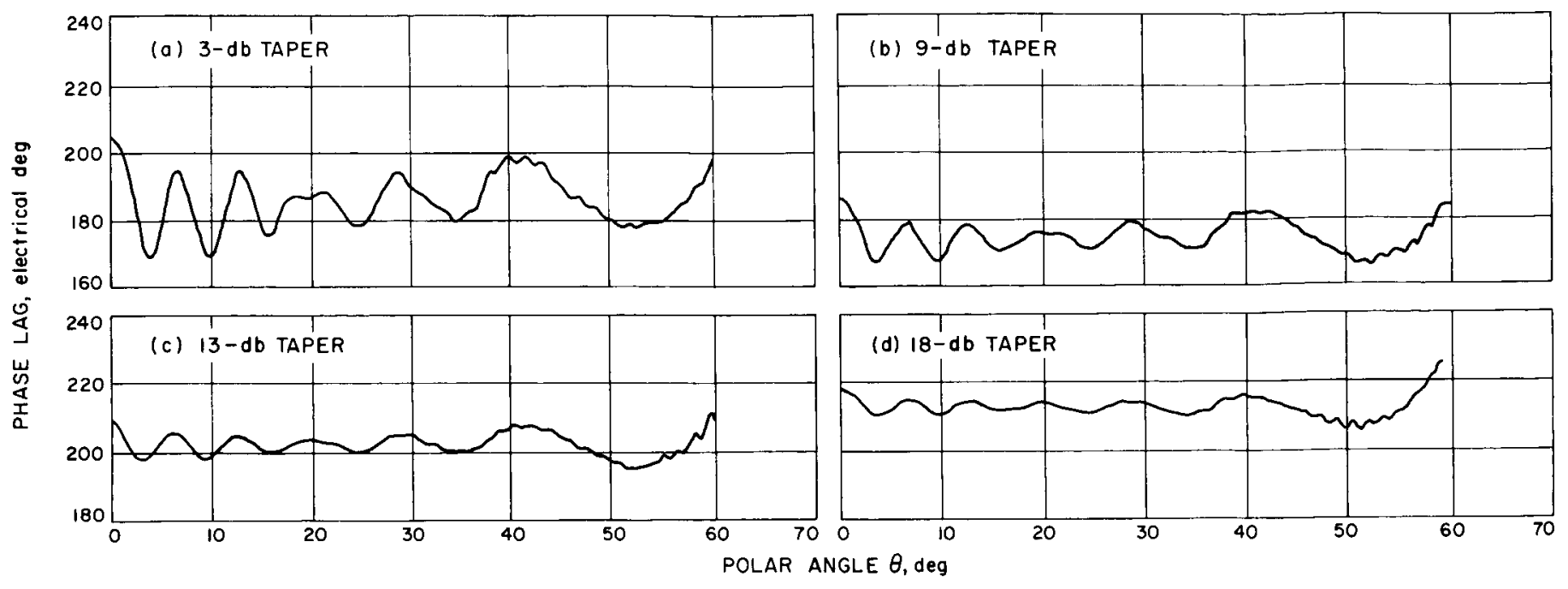

Fig. 8. E-plane phase lag for geometry 1, variable feed-horn faper

\begin{tabular}{|c|c|c|c|c|}
\hline NOMINAL TAPER, db & 3 & 9 & 13 & 18 \\
\hline E-PLANE TAPER, db & 3.07 & 9.20 & 13.02 & 17.24 \\
\hline$H$-PLANE TAPER, db & 3.03 & 9.48 & 13.90 & 19.44 \\
\hline $\begin{array}{c}\text { E-PLANE PHASE } \\
\text { CENTER, } \lambda\end{array}$ & 46.412 & 46.376 & 46.351 & 46.323 \\
\hline $\begin{array}{c}\text { H-PLANE PHASE } \\
\text { CENTER, } \lambda\end{array}$ & 46.397 & 46.356 & 46.325 & 46.284 \\
\hline$\Delta_{E}=C_{E}-C_{G O}, \lambda$ & 0.082 & 0.046 & 0.021 & -0.007 \\
\hline$\Delta_{H}=C_{H}-C_{G O}, \lambda$ & 0.067 & 0.026 & -0.004 & -0.046 \\
\hline$\Delta_{E H}=C_{E}-C_{H}, \lambda$ & 0.015 & 0.020 & 0.026 & 0.039 \\
\hline $\begin{array}{c}\text { PEAK-TO-PEAK PHASE } \\
\text { ERROR }(E-P L A N E), \lambda\end{array}$ & 0.059 & 0.031 & 0.021 & 0.014 \\
\hline
\end{tabular}

Fig. 9. Phase-center characteristics for geometry 1 , variable feed-horn taper

\section{B. Variation of Phase Characteristics with Feed-Horn Position and Subdish Shape}

Figure 10 illustrates Geometries 1, 2, and 3:

\section{Paraboloid}

Diameter

201.67 wavelength

Focal length

Angular semidiameter (at focus)

87.33 wavelength

$60 \mathrm{deg}$

\section{Hyperboloid}

Diameter

19.51 wavelength

Geometry 2:

Secondary focus
57.26 wavelength from paraboloid vertex
Angular semidiameter (at horn)

Eccentricity $21.75 \mathrm{deg}$

Magnification 1.9979

Geometry 1:

Secondary focus

Angular semidiameter (at horn)

Eccentricity

Magnification

41.00 wavelength from paraboloid vertex

Geometry 3:

Secondary focus

Angular semidiameter (at horn)

Eccentricity $9.50 \mathrm{deg}$

Magnification 6.9488

The horn taper remains constant at $9 \mathrm{db}$. Figure 11 illustrates the corresponding phase characteristics. As expected, the mean phase lag is changed as the path length is changed with movement of the horn. However, the phase plots themselves are virtually identical, and, within the computer accuracy, can be superimposed on one another. The phase characteristics are tabulated in Fig. 12. It is evident that movement of the horn and corresponding change of reflector shape with constant reflector size causes virtually no change in the relative phasecenter displacements nor does it affect the peak-to-peak phase error. 


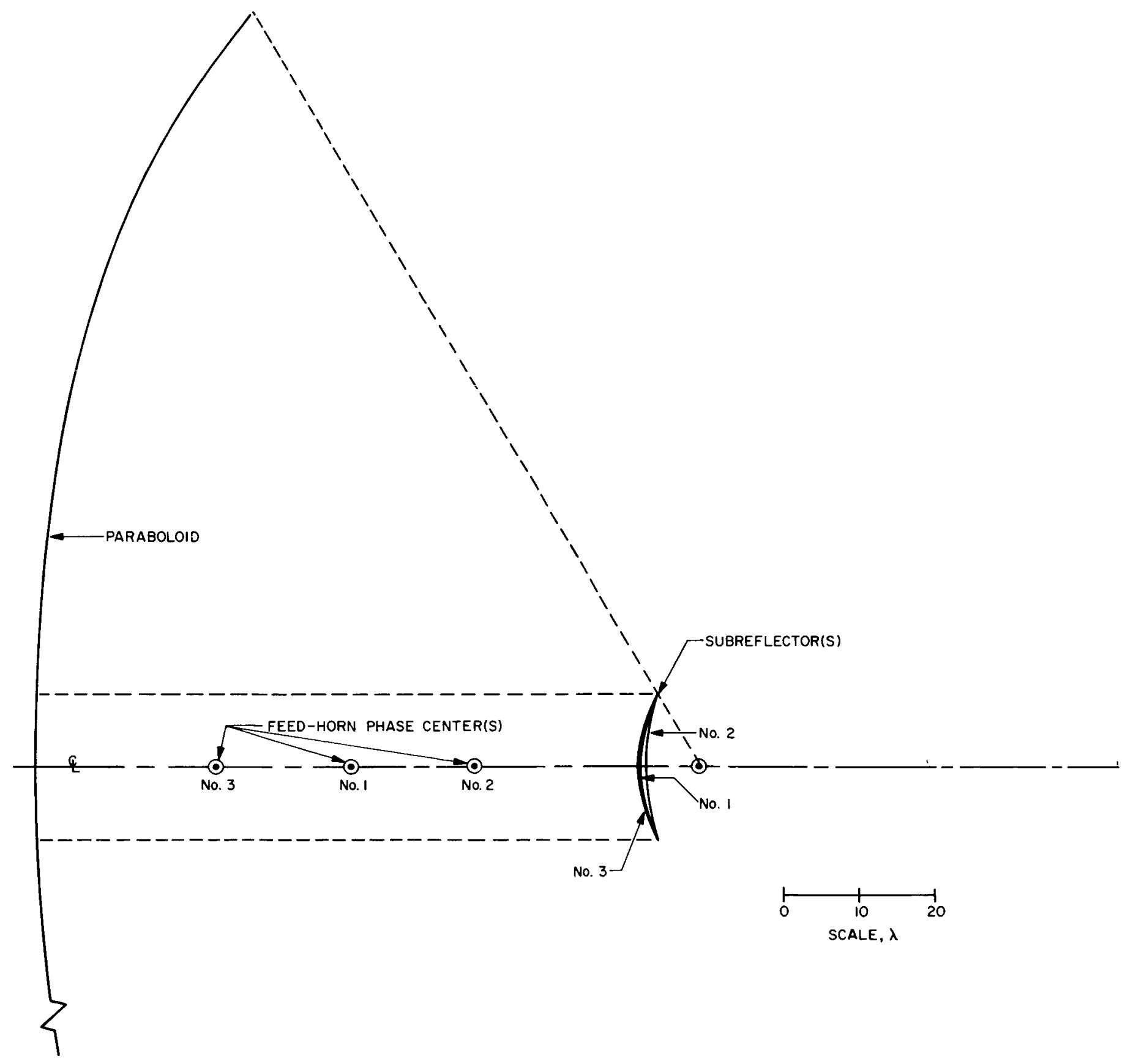

Fig. 10. Geometries 1, 2, and 3 showing variable subreflector shape and variable feed-horn phase center 


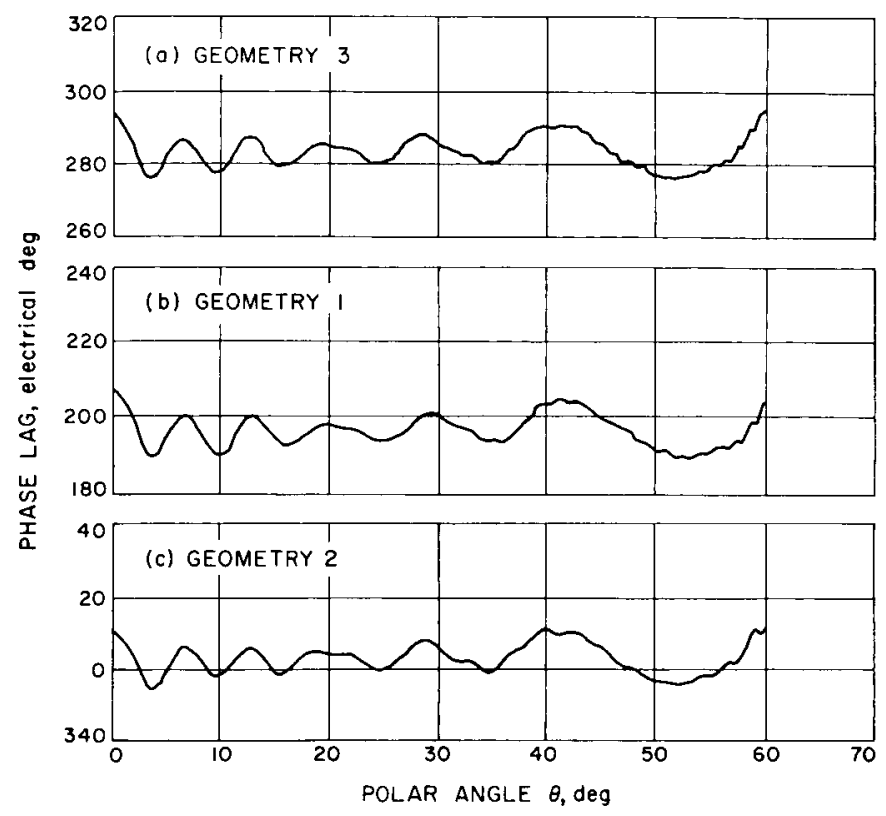

Fig. 11. E-plane phase lag for geometries 1, 2, and 3 (9-db feed-horn taper)

\begin{tabular}{|c|c|c|c|}
\hline GEOMETRY NO. & 3 & 1 & 2 \\
\hline E-PLANE TAPER, db & 9.12 & 9.20 & 9.41 \\
\hline H-PLANE TAPER, db & 9.44 & 9.47 & 9.54 \\
\hline $\begin{array}{c}\text { E-PLANE PHASE } \\
\text { CENTER, } \lambda\end{array}$ & 63.963 & 46.376 & 30.117 \\
\hline $\begin{array}{c}\text { H-PLANE PHASE } \\
\text { CENTER, } \lambda\end{array}$ & 63.944 & 46356 & 30.095 \\
\hline$\triangle_{E}=C_{E}-C_{G O}, \lambda$ & 0.045 & 0.046 & 0.043 \\
\hline$\triangle_{H}=C_{H}-C_{G O}, \lambda$ & 0.026 & 0.026 & 0.021 \\
\hline$\triangle_{E H}=C_{E}-C_{H}, \lambda$ & 0.019 & 0.020 & 0.022 \\
\hline $\begin{array}{c}\text { PEAK-TO-PEAK PHASE } \\
\text { ERROR (E-PLANE), } \lambda\end{array}$ & 0.029 & 0.031 & 0.029 \\
\hline
\end{tabular}

Fig. 12. Phase-center characteristics for geometries 1,2 , and 3 (9-db feed-horn taper)

\section{Variation of Phase Characteristics with Paraboloid F/D}

Figure 13 illustrates Geometries 1, 4, and 5:

\section{Paraboloid}

Diameter

201.67 wavelength

Geometry 5:

Focal length

72.00 wavelength

Angular semidiameter (at focus)
Geometry 1:

Focal length

Angular semidiameter (at focus)

87.33 wavelength

60 deg

Geometry 4:

Focal length

Angular semidiameter (at focus)

108.12 wavelength

$50 \mathrm{deg}$

Hyperboloid

Diameter

19.51 wavelength

Geometry 5:

Secondary focus

Angular semidiameter (at horn)

$.50 \mathrm{deg}$

Eccentricity

Magnification

Geometry 1:

Secondary focus

Angular semidiameter (at horn)

Eccentricity

Magnification

35.53 wavelength from paraboloid vertex

Geometry 4:

Secondary focus

Angular semidiameter (at horn)

41.00 wavelength from paraboloid vertex

$13.50 \mathrm{deg}$

1.5146

4.88

Eccentricity

Magnification

49.76 wavelength from paraboloid vertex

$11 \mathrm{deg}$

1.52042

4.84

With the variation of several geometrical parameters involved, it should be noted that the subdish shape remains essentially constant. In addition, the horn taper remains at $9 \mathrm{db}$. Figure 14 illustrates the corresponding phase characteristics. The phase plots are quite similar, although each 10-deg increment in edge angle adds an additional phase ripple, in spite of the fact that the subdish diameter remains constant. The phase characteristics are tabulated in Fig. 15. An increase in F/D results in a nominal increase in the relative phase-center displacements, although the peak-to-peak phase ripple remains virtually unaffected. 


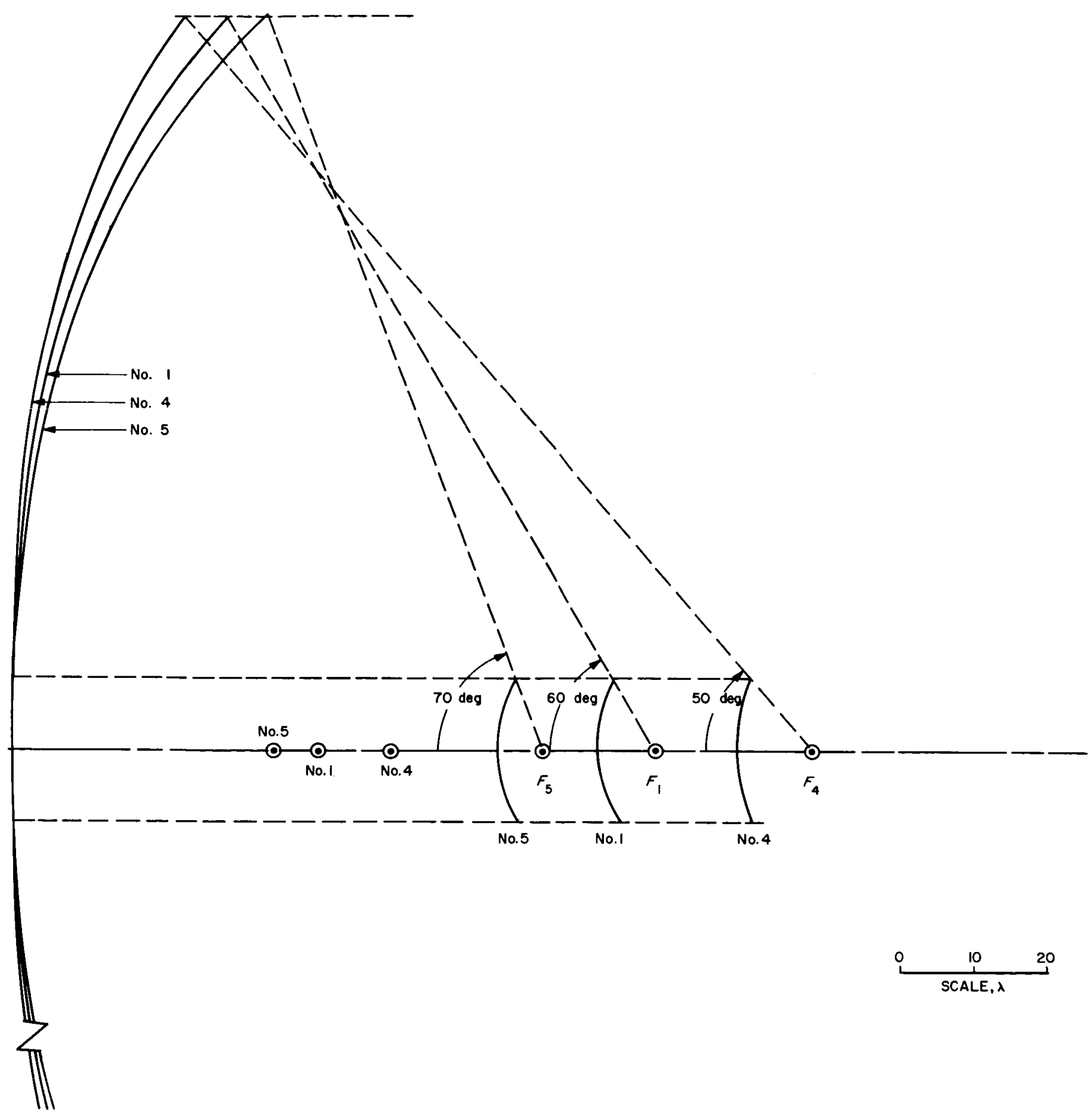

Fig. 13. Geometries 1,4 , and 5 showing variable F/D 


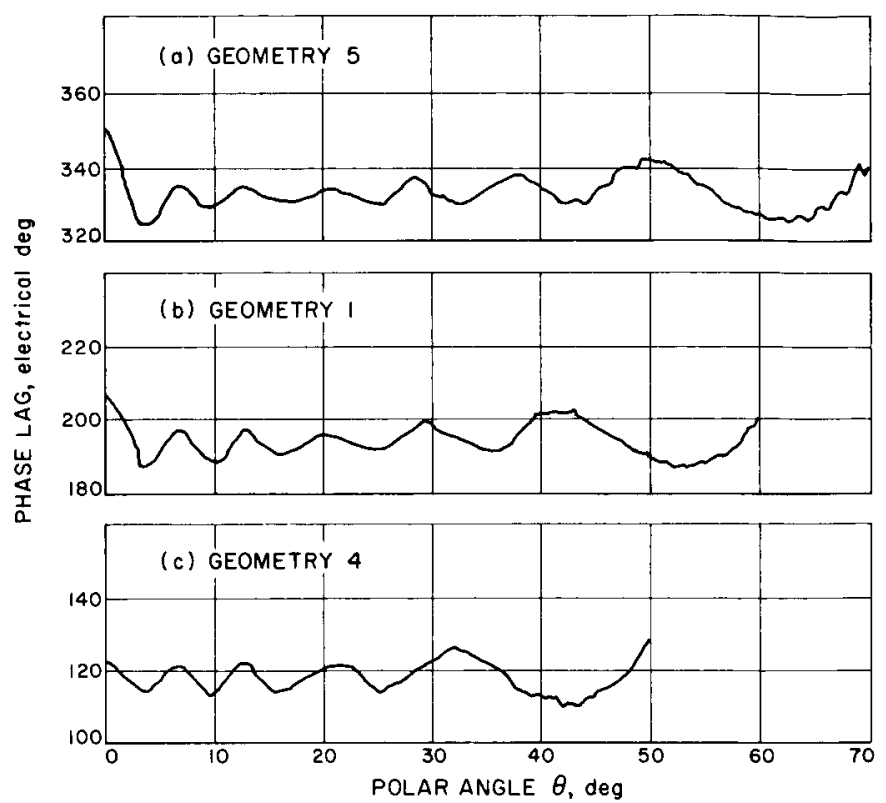

Fig. 14. E-plane phase lag for geometries 1,4 , and 5 (9-db feed-horn taper)

\begin{tabular}{|c|c|c|c|}
\hline GEOME TRY NO. & 5 & 1 & 4 \\
\hline E-PLANE TAPER, do & 9.30 & 9.20 & 9.18 \\
\hline H-PLANE TAPER, db & 9.53 & 9.48 & 9.48 \\
\hline $\begin{array}{c}\text { E-PLANE PHASE } \\
\text { CENTER, } \lambda\end{array}$ & 36.514 & 46.376 & 58.414 \\
\hline $\begin{array}{c}\text { H-PLANE PHASE } \\
\text { CENTER, } \lambda\end{array}$ & 36.496 & 46.356 & 58.391 \\
\hline$\triangle_{E}=C_{E}-C_{G O}, \lambda$ & 0.037 & 0.046 & 0.052 \\
\hline$\Delta_{H}=C_{H}-C_{G O}, \lambda$ & 0.019 & 0.026 & 0.029 \\
\hline$\Delta_{E H}=C_{E}-C_{H}, \lambda$ & 0.018 & 0.020 & 0.023 \\
\hline $\begin{array}{c}\text { PEAK-TO-PEAK PHASE } \\
\text { ERROR }(E-P L A N E), \lambda\end{array}$ & 0.028 & 0.031 & 0.026 \\
\hline
\end{tabular}

Fig. 15. Phase-center characteristics for geometries 1,4 , and 5 (9-db feed-horn taper)

\section{Phase Characteristics for Illumination by TE 1 -Mode Horn}

The geometry considered is identical to Geometry 1 . However, the feed horn is excited in the $\mathrm{TE}_{1}$-mode rather than the dual-mode configuration. The horn radius is such that the $H$-plane taper at the subdish edge is $9.48 \mathrm{db}$, but the $E$-plane taper is $20.17 \mathrm{db}$. Consequently, the horn pattern does not have rotational symmetry. Figure 16 is a comparison of the $E$ - and $H$-plane phase patterns, resulting from the $\mathrm{TE}_{11}$-mode illumination, and the corresponding patterns, resulting from the dual-mode illumination. Although the phase patterns in the two planes show larger differences for the $\mathrm{TE}_{11}$-mode, these differences occur at sufficiently wide angles that the magnitude taper should reduce their effect. The phase characteristics are tabulated in Fig. 17. The relative phase-center displacements for the $\mathrm{TE}_{11}$-mode illumination are not excessively large. The peak-to-peak phase

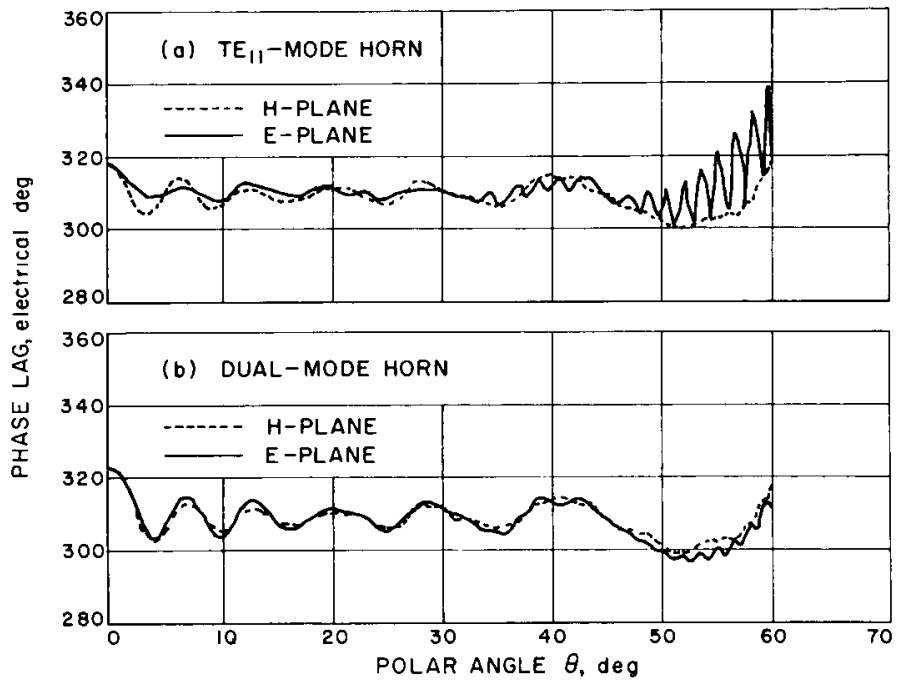

Fig. 16. Comparison of phase lag for geometry 1 with $T E_{11}$-mode and dual-mode excitation

\begin{tabular}{|c|c|c|}
\hline FEED HORN & TE $_{11}$ MODE & DUAL MODE \\
\hline E-PLANE TAPER, db & 20.17 & 9.20 \\
\hline H-PLANE TAPER, db & 9.48 & 9.48 \\
\hline E-PLANE PHASE CENTER, $\lambda$ & 46.309 & 46.376 \\
\hline H-PLANE PHASE CENTER, $\lambda$ & 46.350 & 46.356 \\
\hline$\triangle_{E}=C_{E}-C_{G O}, \lambda$ & -0.020 & 0.046 \\
\hline$\triangle_{H}=C_{H}-C_{G O}, \lambda$ & 0.024 & 0.026 \\
\hline$\triangle_{E H}=C_{E}-C_{H}, \lambda$ & -0.045 & 0.020 \\
\hline $\begin{array}{c}\text { PEAK }- \text { TO-PEAK PHASE } \\
\text { ERROR (E-PLANE), } \lambda\end{array}$ & 0.015 & 0.031 \\
\hline
\end{tabular}

Fig. 17. Comparison of phase-center characteristics for geometry 1 with $\mathrm{TE}_{\mathrm{1} 1}$-mode and dualmode excitation 
error has decreased because of the increased amplitude taper in the $E$-plane, as discussed earlier.

\section{E. Phase Characteristics for Twice the Frequency}

Geometry 1 is again used, but the frequency is doubled. The horn aperture radius is halved so that the illumination taper at the edge of the subdish remains at $9 \mathrm{db}$. Figure 18 is a comparison of the resulting $E$-plane phase plot with the corresponding phase plot at the original frequency. Clearly, the number of phase ripples has

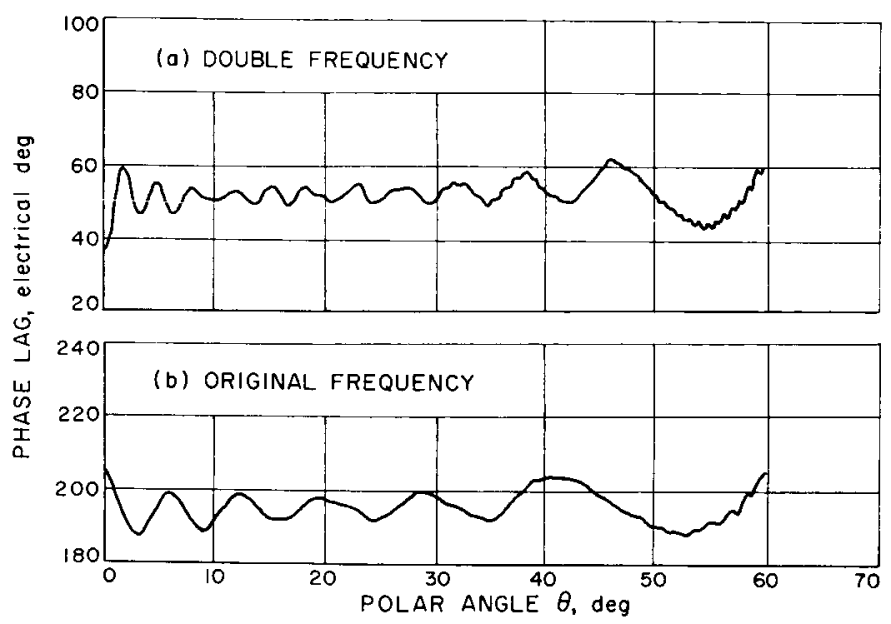

Fig. 18. Comparison of E-plane phase lag for geometry 1 (double frequency) and geometry 1 (original frequency)

\begin{tabular}{|l|c|c|}
\hline GEOMETRY & $\begin{array}{c}\text { DOUBLE } \\
\text { FREQUENCY }\end{array}$ & $\begin{array}{c}\text { ORIGINAL } \\
\text { FREQUENCY }\end{array}$ \\
\hline E-PLANE TAPER, db & 9.20 & 9.20 \\
\hline H-PLANE TAPER, db & 9.48 & 9.48 \\
\hline E-PLANE PHASE CENTER, $\lambda$ & 92.692 & 46.376 \\
\hline$H$-PLANE PHASE CENTER, $\lambda$ & 92.681 & 46.356 \\
\hline$\Delta_{E}=C_{E}-C_{G O}, \lambda$ & 0.032 & 0.046 \\
\hline$\Delta_{H}=C_{H}-C_{G O} \lambda$ & 0.020 & 0.026 \\
\hline$\triangle_{E H}=C_{E}-C_{H}, \lambda$ & 0.012 & 0.020 \\
\hline $\begin{array}{c}\text { PEAK }- \text { TO-PEAK PHASE } \\
\text { ERROR }(E-P L A N E), \lambda\end{array}$ & 0.022 & 0.031 \\
\hline
\end{tabular}

Fig. 19. Comparison of phase-center characteristics for geometry 1 (double frequency) and geometry 1 (original frequency) increased (doubled), although the peak-to-peak value has been reduced. The tabulated phase characteristics in Fig. 19 indicate both reduced phase-center displacements and reduced ripple magnitude. This result is expected, because the frequency increase should more closely approximate the geometrical-optics condition.

\section{F. Phase Characteristics for Minimum-Blocking Condition}

In each of the previous geometries, the subdish size determined the amount of aperture blocking. However, it is evident that under certain conditions the horn aperture will block an even greater fraction of the paraboloid aperture. It has been shown (Ref. 10) that minimum aperture blocking is achieved when the subdish size and feed-horn shadow are equal. An example of such a minimum-blocking geometry is illustrated in Fig. 20.

\section{Paraboloid}

Diameter

Focal length

Angular semidiameter (at focus)

Hyperboloid

Diameter

Secondary focus

Angular semidiameter (at horn)

Eccentricity

Magnification
201.67 wavelength

87.33 wavelength

$60 \mathrm{deg}$

12.75 wavelength

41.00 wavelength from paraboloid vertex
$8.50 \mathrm{deg}$

1.2954

7.77
Figure 21 shows a comparison of the resulting $E$-plane phase plot with the corresponding plot for Geometry 1. The ripple magnitude is somewhat increased, and the number of ripples is decreased. The tabulated phase characteristics (Fig. 22) indicate no great differences between the two. It should be mentioned that the minimumblocking condition may not be desirable in a low-noise antenna, because the relative smallness of the subdish may produce excessive backward spillover. 


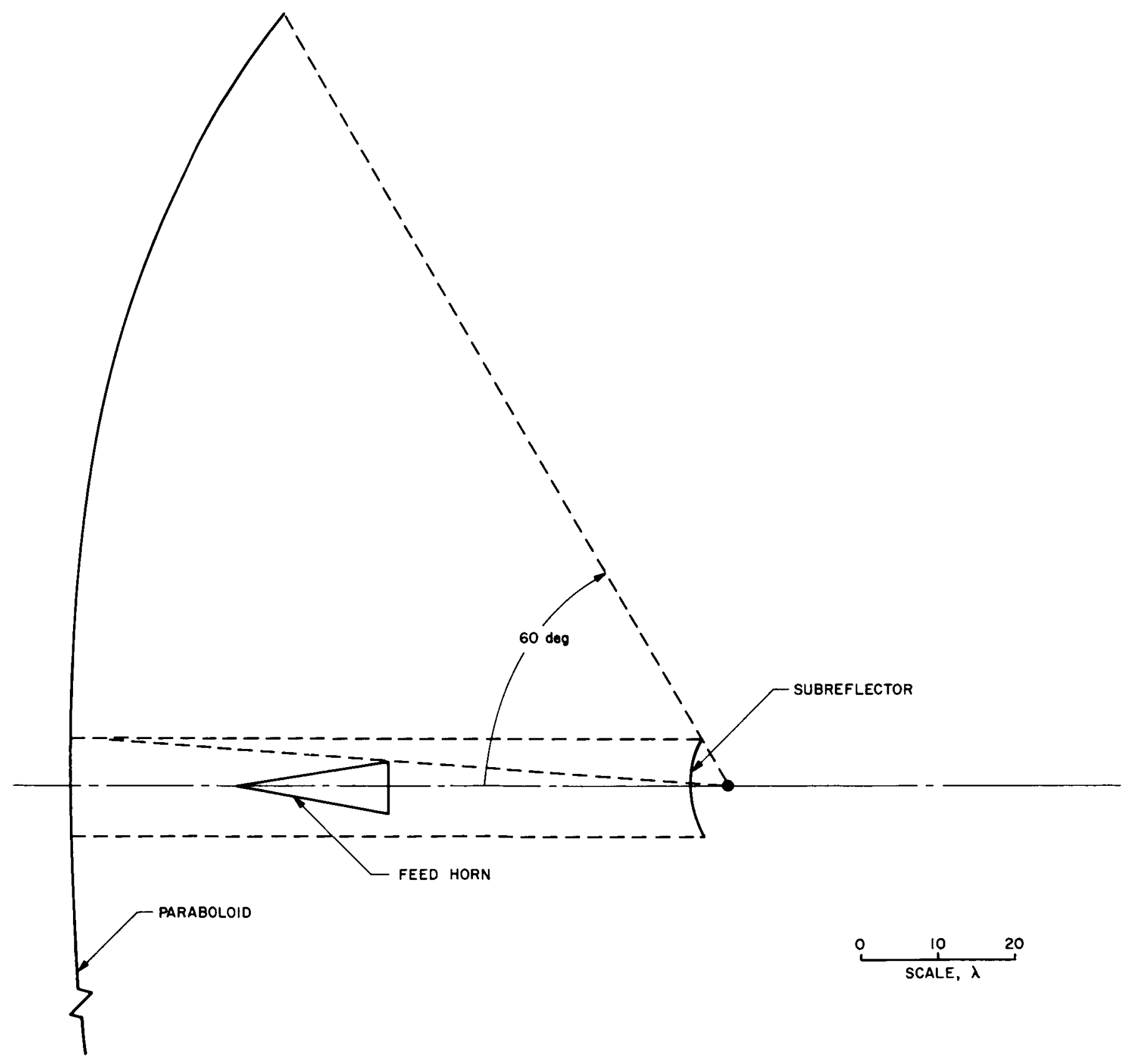

Fig. 20. Geometry for minimum-blocking condition (9-db feed-horn taper) 


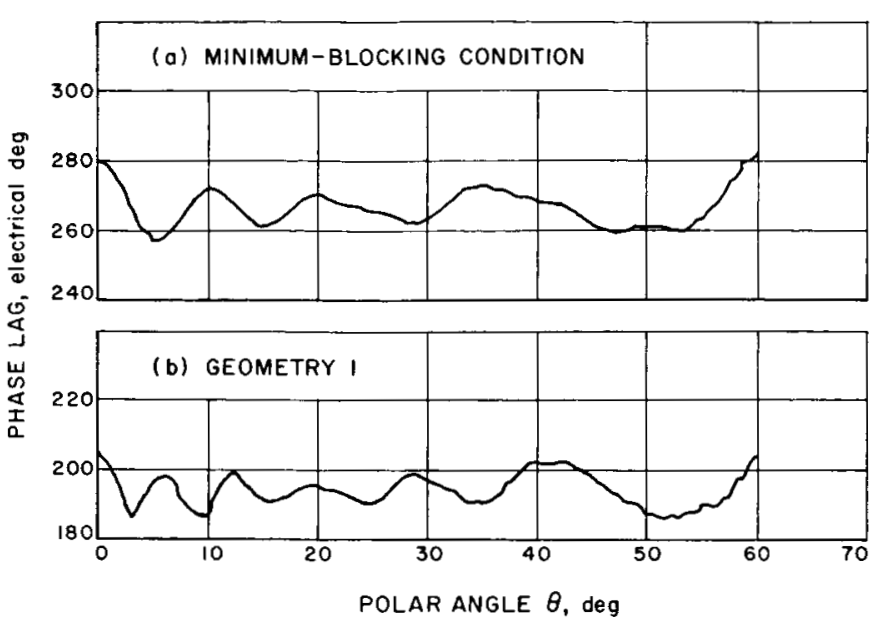

Fig. 21. Comparison of E-plane phase for minimumblocking condition and geometry 1 19-db feedhorn taper)

\begin{tabular}{|c|c|c|}
\hline GEOMETRY & $\begin{array}{c}\text { MINIMUM-BLOCKING } \\
\text { CONDITION }\end{array}$ & NO.I \\
\hline E-PLANE TAPER, db & 9.07 & 9.20 \\
\hline H-PLANE TAPER, db & 9.40 & 9.48 \\
\hline E-PLANE PHASE CENTER, $\lambda$ & 46.379 & 46.376 \\
\hline H-PLANE PHASE CENTER, $\lambda$ & 46.350 & 46.356 \\
\hline$\Delta_{E}=C_{E}-C_{G O}, \lambda$ & 0.049 & 0.046 \\
\hline$\Delta_{H}=C_{H}-C_{G O}, \lambda$ & 0.021 & 0.026 \\
\hline$\triangle_{E H}=C_{E}-C_{H}, \lambda$ & 0.028 & 0.020 \\
\hline $\begin{array}{c}\text { PEAK-TO-PEAK PHASE } \\
\text { ERROR (E-PLANE), } \lambda\end{array}$ & 0.037 & 0.031 \\
\hline
\end{tabular}

Fig. 22. Comparison of phase-center characteristics for minimum-blocking condition and geometry 1 (9-db feed-horn taper)

\section{FIELDS REFLECTED FROM THE PARABOLOID}

The second half of the problem is now to compute the fields reflected from the paraboloid (Fig. 23). Accurate, analytical expressions from Section II are available to describe the fields illuminating the paraboloid. The phase center of the fields scattered from the subdish will be placed at the focus $F$, so that an approximately constant-

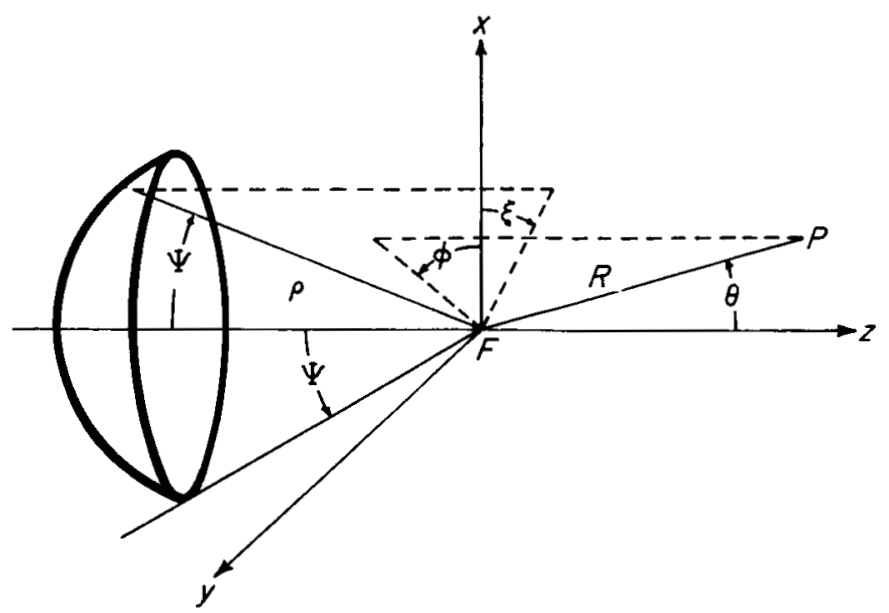

Fig. 23. Paraboloid geometry phase spherical wave will be incident on the paraboloid. This incident field is given in Eq. 3:

$$
\bar{E}_{i n c}=\frac{e^{i k p}}{p}\left[E(\psi) \sin \xi a_{\psi}+H(\psi) \cos \xi \bar{a}_{\xi}\right]
$$

where $E(\psi)$ and $H(\psi)$ are equal in magnitude to $f_{1}(\theta)$ and $k_{1}(\theta)$ of Eq. 2, but they have different phases because of the phase-center transformation.

Application of the reflection laws for local plane waves yields the field in the aperture of the paraboloid. ${ }^{3}$ This aperture field is expressed in Eq. 4:

$$
\begin{aligned}
\bar{E}_{a p}= & \frac{e^{i 2 k f}}{p}\left\{[H(\psi)-E(\psi)] \sin \xi \cos \xi \bar{a}_{x}\right. \\
& \left.+\left[H(\psi) \sin ^{\prime} \xi+E(\psi) \cos ^{2} \xi\right] \bar{a}_{y}\right\}
\end{aligned}
$$

Because of the diffraction phase-ripples of the incident field, this aperture field is not completely constant in

\footnotetext{
${ }^{3}$ Taken to be in the focal plane.
} 
phase, and, outside of the principal planes, there is a cross-polarized $x$-component of the field. Furthermore, since $E(\psi)$ and $H(\psi)$ are phasors, a cross-polarized component of the aperture field can result from differences in the $E$ - and $H$-plane patterns, as well as the familiar cross-polarized component from differences in the $E$ - and $H$-plane amplitude patterns.

The aperture distribution of the cross-polarized field is plotted in Fig. 24. The decibel values are relative to the

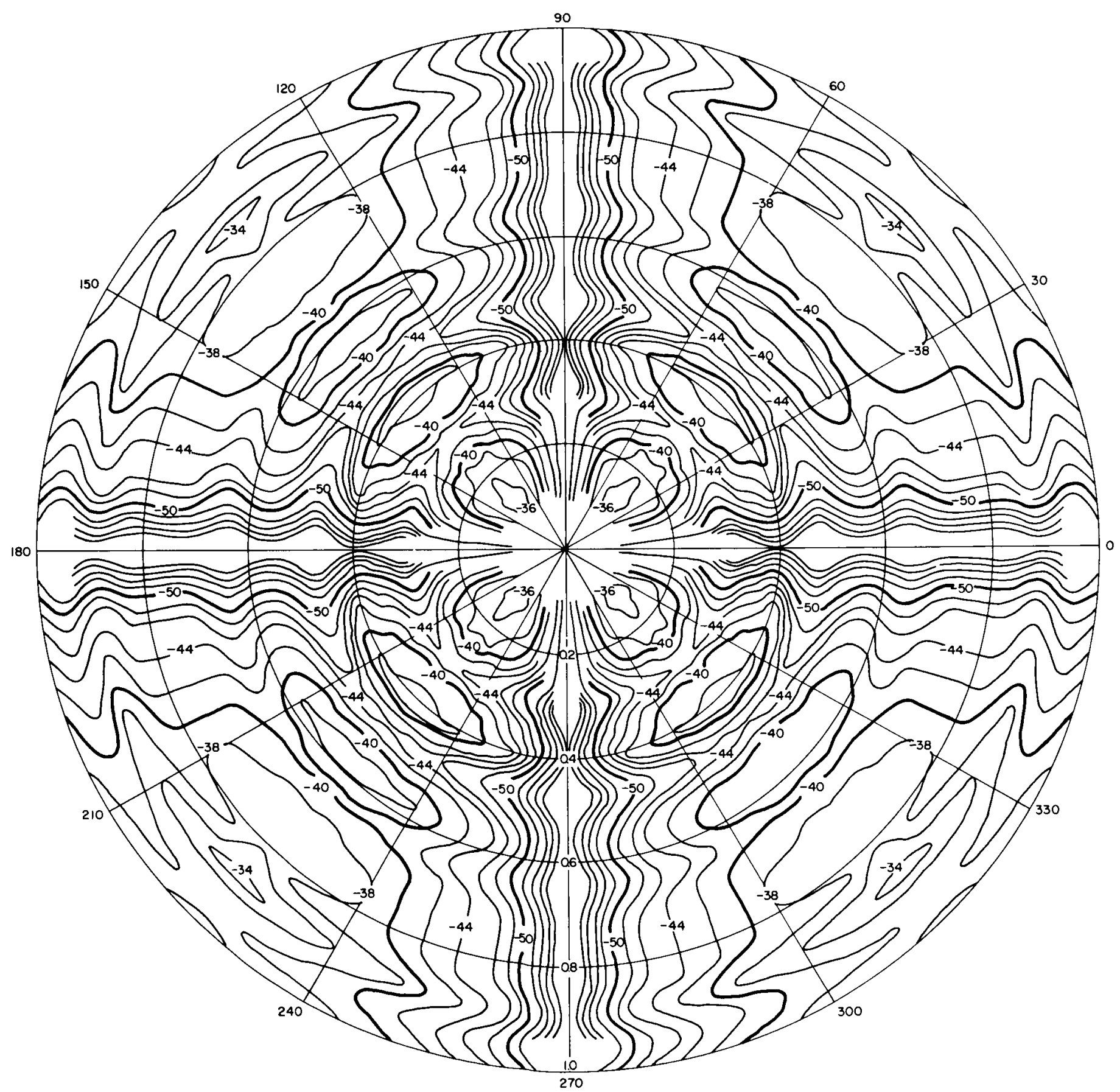

Fig. 24. Aperture contours of cross-polarized field (geometry 1, 9-db feed-horn taper) 
peak value of the normalized component. This example is for Geometry 1 , with a 9-db subdish illumination taper. Quite evidently the cross-polarization peaks in the diagonal planes are very small relative to the normally polarized component. The cross-polarized component of the aperture field does not contribute to the axial field, but instead generates four cross-polarized lobes midway between the $E$ - and $H$-planes of the secondary pattern.

Integration of the aperture field yields the axial field at great distances from the antenna:

(a) AXIAL FIELD

$$
\begin{aligned}
\bar{E}(0,0)=\bar{a}_{y} \frac{e^{i k R}}{R} & \left\{\frac{-2 i f \pi e^{i \vartheta k f}}{\lambda}\right. \\
& \left.\int_{\psi \text { min }}^{\psi}[E(\psi)+H(\psi)] \tan \frac{\psi}{2} d \psi\right\}
\end{aligned}
$$

The effects of feed-support blockage and forward spillover $^{4}$ have not been included in this expression, although

${ }^{4}$ Estimates in Ref. 1 indicate forward spillover contribution to be a few percent, depending primarily on the nature of the feedhorn pattern. subdish blockage is included. It is evident that the fraction of the total power that is converted into a crosspolarized component of the aperture field detracts from the axial gain.

In crder to evaluate the relative importance of aperture phase-error and associated cross-polarization, an idealized aperture field has been postulated that is identical to the actual aperture field in magnitude, but constant in phase. The axial field from this idealized aperture distribution is

\section{(b) AXIAL REFERENCE FIELD}

$$
\begin{array}{r}
\bar{E}_{r e f}(0,0)=\bar{a}_{y} \frac{e^{i k R}}{R}\left\{\frac{-2 i f_{\pi} e^{i \vartheta k f}}{\lambda}\right. \\
\left.\int_{\psi \text { min }}^{\psi}[|E(\psi)|+|H(\psi)|] \tan \frac{\psi}{2} d \psi\right\}
\end{array}
$$

The loss in axial gain due to phase-error and associated cross-polarization is then defined as the ratio of these two fields, in decibels

(c) PHASE-ERROR LOSS

$$
L_{p}(d b) \equiv 20 \log _{10}\left|\frac{\bar{E}(0,0)}{\bar{E}_{r e f}(0,0)}\right|
$$

\section{v. CALCULATION OF GAIN CHARACTERISTICS}

The preceding expressions have been used to evaluate the effects of phase ripple on overall antenna gain.

\section{A. Variation of Gain Characteristics with Taper of Subdish Illumination}

The effects of amplitude taper on system gain have been known for many years. However, it was demonstrated previously that feed-horn illumination tapering at the edge of the subdish also reduces the peak-to-peak ripple, which should also affect system gain. Figure 25 contains a tabulation of the gain characteristics calculated for Geometry 1 with varying feed-horn taper. The

\begin{tabular}{|l|l|l|l|l|}
\hline NOMINAL TAPER, db & \multicolumn{1}{|c|}{3} & \multicolumn{1}{c|}{9} & \multicolumn{1}{c|}{13} & 18 \\
\hline $\begin{array}{c}\text { TAPER AT PARABO- } \\
\text { LOID EDGE, db }\end{array}$ & 10.0 & 14.3 & 17.5 & 21.0 \\
\hline GAIN $\left(C_{E}\right)$ & $18.07 \times 10^{4}$ & $29.57 \times 10^{4}$ & $29.647 \times 10^{4}$ & $27.84 \times 10^{4}$ \\
\hline EFFICIENCY $\left(C_{E}\right), \%$ & 45.02 & 73.66 & 73.86 & 69.36 \\
\hline $\begin{array}{l}\text { PHASE-ERROR LOSS } \\
\left(C_{E}\right), \mathrm{db}\end{array}$ & 0.055 & 0.024 & 0.016 & 0.013 \\
\hline GAIN $\left(C_{H}\right)$ & $18.06 \times 10^{4}$ & $29.56 \times 10^{4}$ & $29.64 \times 10^{4}$ & $27.83 \times 10^{4}$ \\
\hline EFFICIENCY $\left(C_{H}\right), \%$ & 45.00 & 73.64 & 73.84 & 69.33 \\
\hline $\begin{array}{l}\text { PHASE-ERROR LOSS } \\
\left(C_{H}\right), \text { db }\end{array}$ & 0.057 & 0.026 & 0.017 & 0.015 \\
\hline
\end{tabular}

Fig. 25. Gain characteristics for geometry 1, variable feed-horn taper 
aperture taper varies from 10.0 to 21.6 , and the subsequent aperture efficiency varies from $45 \%$ to a maximum near $74 \% .^{5}$ The gains were calculated for both the $E$-plane phase center of the illuminating fields located at the paraboloid focus and the $H$-plane phase center located at the focus. Negligible difference was calculated. The phase-error loss, defined earlier by Eq. 7, was only a small fraction of a decibel, and it decreased with increasing taper as the magnitude of the phase ripple decreased. However, for the rotationally symmetric illumination fields of the dual-mode feed horn being considered, the phase-error effect is minute compared with the amplitude-taper effect.

\section{B. Variation of Gain Characteristics with Feed-Horn Position and Subdish Shapes}

The gain characteristics for Geometries 1,2, and 3 are tabulated in Fig. 26. The feed-horn taper remains constant at $9 \mathrm{db}$. The feed-horn position is seen to have an effect of only a small fraction of a percent on the overall antenna efficiency. This is consistent with the virtually identical phase patterns for these three geometries. Again, the phase-error loss is extremely small.

\begin{tabular}{|c|c|c|c|}
\hline GEOMETRY NO. & 3 & 1 & 2 \\
\hline $\begin{array}{c}\text { TAPER AT PARABO- } \\
\text { LOID EDGE, db }\end{array}$ & 14.6 & 14.3 & 14.8 \\
\hline GAIN $\left(C_{E}\right)$ & $29.59 \times 10^{4}$ & $29.57 \times 10^{4}$ & $29.29 \times 10^{4}$ \\
\hline EFFICIENCY $\left(C_{E}\right), \%$ & 73.72 & 73.66 & 72.98 \\
\hline $\begin{array}{c}\text { PHASE-ERROR LOSS } \\
\left(C_{E}\right), \mathrm{db}\end{array}$ & 0.025 & 0.024 & 0.024 \\
\hline GAIN $\left(C_{H}\right)$ & $29.58 \times 10^{4}$ & $29.56 \times 10^{4}$ & $29.28 \times 10^{4}$ \\
\hline EFFICIENCY $\left(C_{H}\right), \%$ & 73.70 & 73.64 & 72.95 \\
\hline PHASE-ERROR LOSS & 0.026 & 0.026 & 0.026 \\
\hline$\left(C_{H}\right), \mathrm{db}$ & & & \\
\hline
\end{tabular}

Fig. 26. Gain characteristics for geometries 1, 2, and 3 (9-db feed-horn taper)

\section{Variation of Gain Characteristics with Paraboloid F/D}

The gain characteristics for Geometries 1, 4, and 5 are tabulated in Fig. 27. The feed-horn illumination taper is again $9 \mathrm{db}$. The phase-error loss is extremely small. However, it is worthy of note that although the $F / D$ value

\footnotetext{
${ }^{5}$ Antenna gain could be calculated because precise expressions for the total power radiated by the feed horns were available.
}

\begin{tabular}{|c|c|c|c|}
\hline GEOMETRY NO. & 5 & 1 & 4 \\
\hline $\begin{array}{c}\text { TAPER AT PARABO- } \\
\text { LOID EDGE, db }\end{array}$ & 13.97 & 14.3 & 13.6 \\
\hline GAIN $\left(C_{E}\right)$ & $29.57 \times 10^{4}$ & $29.57 \times 10^{4}$ & $29.31 \times 10^{4}$ \\
\hline EFFICIENCY $\left(C_{E}\right) \%$ & 73.67 & 73.66 & 73.02 \\
\hline $\begin{array}{c}\text { PHASE-ERROR LOSS } \\
\left(C_{E}\right), \mathrm{db}\end{array}$ & 0.001 & 0.024 & 0.012 \\
\hline GAIN $\left(C_{H}\right)$ & $29.57 \times 10^{4}$ & $2956 \times 10^{4}$ & $29.33 \times 10^{4}$ \\
\hline EFFICIENCY $\left(C_{H}\right) \%$ & 73.67 & 73.64 & 73.06 \\
\hline $\begin{array}{c}\text { PHASE-ERROR LOSS } \\
\left(C_{H}\right), \mathrm{db}\end{array}$ & 0.001 & 0.026 & 0.010 \\
\hline
\end{tabular}

Fig. 27. Gain characteristics for geometries 1, 4, and 5 (9-db feed-horn taper)

ranges from 0.357 to 0.536 , the gain (and efficiency) change less than $1 \%$. The significant cross-polarization loss usually associated with deep dishes is not present in a Cassegrainian antenna with a magnification as large as the value considered (4.8).

\section{Gain Characteristics for Illumination by Circular $\mathbf{T E}_{11}$-Mode Horn}

Geometry 1 is illuminated by a $\mathrm{TE}_{11}$-mode horn. The illumination pattern is no longer symmetric in magnitude or phase. Figure 28 presents a tabulation of the gain characteristics compared with the same geometry illuminated by a dual-mode horn. The efficiency is appreciably reduced, because the illumination pattern is no longer symmetric. The phase-error loss, although small, is somewhat larger because of increased separation between $E$ and $H$-plane phase centers of the illumination pattern.

\begin{tabular}{|l|l|l|}
\hline \multicolumn{1}{|c|}{ FEED HORN } & TE $_{11}$ MODE & DUAL MODE \\
\hline TAPER AT PARABOLOID EDGE, db & 17.14 & 14.3 \\
\hline GAIN $\left(C_{E}\right)$ & $26.66 \times 10^{4}$ & $29.57 \times 10^{4}$ \\
\hline EFFICIENCY $\left(C_{E}\right), \%$ & 66.42 & 73.66 \\
\hline PHASE-ERROR LOSS $\left(C_{E}\right), \mathrm{db}$ & 0.098 & 0.024 \\
\hline GAIN $\left(C_{H}\right)$ & $26.69 \times 10^{4}$ & $29.56 \times 10^{4}$ \\
\hline EFFICIENCY $\left(C_{H}\right), \%$ & 66.49 & 73.64 \\
\hline PHASE-ERROR LOSS $\left(C_{H}\right), \mathrm{db}$ & 0.093 & 0.026 \\
\hline
\end{tabular}

Fig. 28. Comparison of gain characteristics for geometry 1 with TE $_{11}$-mode and dualmode excitation 


\section{E. Gain Characteristics for Twice the Frequency}

The gain characteristics are tabulated in Fig. 29 for Geometry $l$ at double the frequency. For comparison, the characteristics for the original frequency are also included. The efficiency has increased by about $1 \frac{1}{2} \%$. This is attributed to a decrease in the amplitude ripples, since, although the phase ripples have also decreased, the phase-error loss is only slightly lowered.

\begin{tabular}{|l|l|l|}
\hline \multicolumn{1}{|c|}{ GEOMETRY } & $\begin{array}{c}\text { DOUBLE } \\
\text { FREQUENCY }\end{array}$ & $\begin{array}{c}\text { ORIGINAL } \\
\text { FREQUENCY }\end{array}$ \\
\hline TAPER AT PARABOLOID EDGE, db & 14.84 & 14.3 \\
\hline GAIN $\left(C_{E}\right)$ & $121.10 \times 10^{4}$ & $29.57 \times 10^{4}$ \\
\hline EFFICIENCY $\left(C_{E}\right), \%$ & 75.42 & 73.66 \\
\hline PHASE-ERROR LOSS $\left(C_{E}\right), \mathrm{db}$ & 0.021 & 0.024 \\
\hline GAIN $\left(C_{H}\right)$ & $121.08 \times 10^{4}$ & $29.56 \times 10^{4}$ \\
\hline EFFICIENCY $\left(C_{H}\right), \%$ & 75.40 & 73.64 \\
\hline PHASE-ERROR LOSS $\left(C_{H}\right), \mathrm{db}$ & 0.023 & 0.026 \\
\hline
\end{tabular}

Fig. 29. Comparison of gain characteristics for geometry 1 (double frequency) and geometry 1 (original frequency)

\section{F. Gain Characteristics for Minimum-Blocking Condition}

The gain characteristics for the minimum-blocking condition are tabulated in Fig. 30. For comparison, a tabulation of the characteristics of Geometry 1 with a comparable $9 \mathrm{db}$ illumination taper are included. However, because less than $1 \%$ of the aperture in Geometry 1

\begin{tabular}{|l|c|c|}
\hline \multicolumn{1}{|c|}{ GEOMETRY } & $\begin{array}{c}\text { MINIMUM-BLOCKING } \\
\text { CONDITION }\end{array}$ & NO.I \\
\hline TAPER AT PARABOLOID EDGE, db & 13.6 & 14.3 \\
\hline GAIN $\left(C_{E}\right)$ & $29.35 \times 10^{4}$ & $29.57 \times 10^{4}$ \\
\hline EFFICIENCY $\left(C_{E}\right), \%$ & 73.12 & 73.66 \\
\hline PHASE-ERROR LOSS $\left(C_{E}\right), \mathrm{db}$ & 0.030 & 0.024 \\
\hline GAIN $\left(C_{H}\right)$ & $29.34 \times 10^{4}$ & $29.56 \times 10^{4}$ \\
\hline EFFICIENCY $\left(C_{H}\right), \%$ & 73.09 & 73.64 \\
\hline PHASE-ERROR LOSS $\left(C_{H}\right), \mathrm{db}$ & 0.031 & 0.026 \\
\hline
\end{tabular}

Fig. 30. Comparison of gain characteristics for minimum-blocking condition and geometry 1 (9-db feed-horn taper) was blocked, the improvement achieved by minimumblocking design is considerably less than might have been expected. In fact, the gain and efficiency of the minimum-blocked aperture are slightly less $(0.54 \%)$ than for Geometry 1. This slight decrease is attributed to the slightly deteriorated phase characteristics of the minimumblocking design. However, from an engineering point of view, the difference is negligible. It is to be expected that the efficiency of an aperture with significantly more than $1 \%$ blockage can be improved by the minimumblocking design.

In each of the previous numerical examples, the phaseerror losses have been extremely small because the peakto-peak phase ripples have not been greater than 20 or 30 electrical degrees, but, equally as important, the $E$ and $H$-plane phase fluctuations have been nearly equal and in relative synchronism. Consequently, the crosspolarization term in Eq. 4 has been reduced even further than would be expected had the synchronism not existed. A further numerical example is illustrated in Fig. 31.

\begin{tabular}{|l|c|c|c|}
\hline PHASE SHIFT, deg & 0 & 45 & 90 \\
\hline $\begin{array}{c}\text { CROSS POLARIZATION, } \\
\mathrm{bb}\end{array}$ & -36.0 & -7.7 & +0.18 \\
\hline GAIN & $29.65 \times 10^{4}$ & $25.09 \times 10^{4}$ & $14.52 \times 10^{4}$ \\
\hline$\eta, \%$ & 73.9 & 62.5 & 36.2 \\
\hline
\end{tabular}

Fig. 31. Gain and cross-polarization for geometry 1, 13-db feed-horn taper, with phase shift introduced between $E$ - and H-plane

Geometry 1 is illuminated with a 14-db feed horn, and the resulting cross-polarization, gain, and efficiency are tabulated in the first column. In columns two and three, an artificial phase shift of additional 45 and 90 electrical degrees (in addition to the phase ripple) is introduced into the $E$-plane pattern. The resulting cross-polarization increases, because of the phasor difference of the $E$ - and $H$-plane patterns, until, with a 90-deg phase shift, the cross-polarization is equally as big as the normal component, and the gain and efficiency have virtually been cut in half (although the peak-to-peak ripple in each plane is still only about 8 electrical degrees). This example serves to illustrate the desirability for equalizing the $E$ and $H$-plane phase patterns, in addition to reducing the peak-to-peak fluctuations.

\section{G. Feed-System Misalignment}

An additional study has been made of the effects of feed-system misalignment in Geometry 1 with a $9-\mathrm{db}$ 
illumination taper. In each of the previous examples, either the $E$-plane phase center or the $H$-plane phase center of the fields illuminating the paraboloid have been placed at its focus. Figure 32 illustrates the effect of displacing the entire feed system as a unit so that the
$E$-plane phase center lies at distances up to \pm 1 wavelength from the paraboloid focus. A displacement of 1 wavelength reduces the gain by $3 \mathrm{db}$, but displacements up to $1 / 5$ wavelength reduce the gain by only a percent or two. This result has been confirmed experimentally.

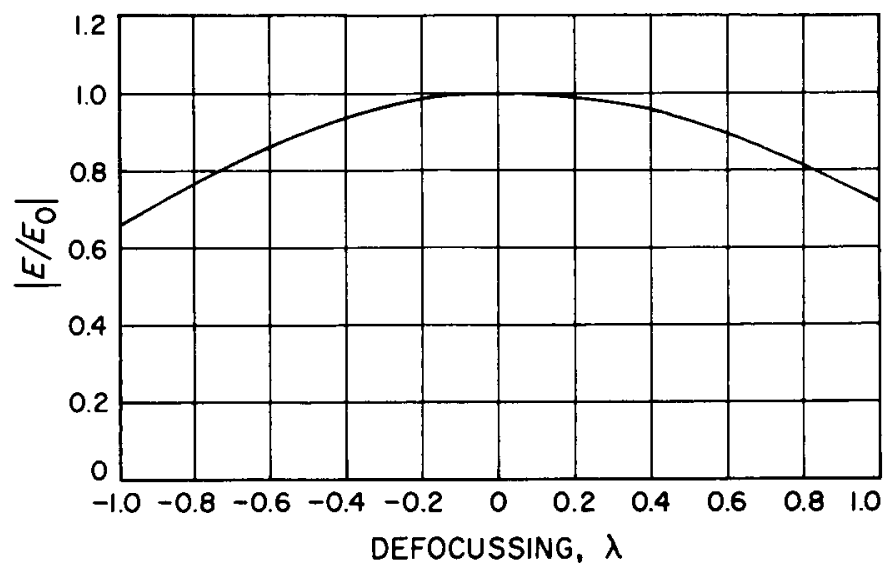

Fig. 32. Effect of feed system misalignment

\section{SUMMARY OF RESULTS AND CONCLUSIONS}

For the inge of feed-horn tapers and antenna parameters, and, I particular, for subdishes with a diameter of at least 19 avelengths or so, the following conclusions have been $\mathrm{r}$ ached:

1. When excited by an ideal, spherical wavefront with a nearly axially symmetric pattern, the field scattered from the subdish possesses $E$ - and $H$-plane phase centers that differ from one another and from the geometricaloptics phase center by only a few percent of a wavelength.

2. The peak-to-peak phase error of the wavefront scattered from the subdish decreases monotonically with increasing illumination taper at the edge of the subdish.

3. An increase in the diameter-to-wavelength ratio of the subdish decreases the size of the peak-to-peak phase errors and the separation between the $E$ - and $H$-plane phase centers.
4. Phase-error loss in axial gain (defined in Eq. 7) will be reduced by reducing the peak-to-peak phase ripples and by equalizing the $E$ - and $H$-plane phase patterns of the scattered field.

5. In general, for a well-designed feed system, the loss in axial gain due to diffractive phase error is only a small fraction of a decibel.

6. In general, placement of the $E$-plane phase center of the scattered field at the focus of the paraboloid does not significantly change the phase-error loss in axial gain that occurs when the $H$-plane phase center is placed at the focus.

7. Feed-system misplacement of 1 wavelength may reduce gain by as much as $3 \mathrm{db}$, although misplacements up to $1 / 5$ wavelength reduce gain by only a percent or so. 


\section{REFERENCES}

1. Potter, P. D., "Unique Feed System Improves Space Antennas," Electronics, Vol. 35, June 22, 1962, pp. 36-40.

2. Jensen, P. A., "A Low-Noise Multimode Cassegrain Monopulse Feed with Polarization Diversity"; paper presented at the Northeast Electronics Research and Engineering Meeting NEREM Record), November 5, 1963.

3. Fitzgerald, W. D., Lynn, V. L., and Keeping, K. J., "Experimental Evaluation of a 1000-Wavelength Antenna," Lincoln Laboratory Report 46G-4, Massachusetts Institute of Technology, May 13, 1963.

4. Stacey, J. M., and Epstein, E. E., "A Precision Radio-Astronomical Antenna for Millimeter Wavelength Observations"; paper presented at the meeting of the American Astronomical Society, Flagstaff, Arizona, June 24-27, 1964.

5. Potter, P. D., "The Aperture Efficiency of Large Paraboloidal Antennas as a Function of Their Feed-System Radiation Characteristics," Technical Report No. 32-1 49, Jet Propulsion Laboratory, Pasadena, California, September 25, 1961.

6. Silver, S., "Microwave Antenna Theory and Design," McGraw-Hill Book Co., Inc., New York, M.I.T. Radiation Laboratory Series, Vol. 12, 1949.

7. Rusch, W.V.T., "Scattering from a Hyperboloidal Reflector in a Cassegrainian Feed System," IEEE Transactions on Antennas and Propagation, Vol. P-11, No. 4, July 1963, pp. 414-421.

8. Potter, P. D., "A New Horn Antenna with Suppressed Sidelobes and Equal Beamwidths," Microwave Journal, Vol. VI, No. 6, June 1963, pp. 71-78.

9. Cumming, R. C., "The Serrodyne Frequency Translator," Proceedings of the IRE, Vol. 15, February 1957, pp. 175-186.

10. Hannan, P. W., "Microwave Antennas Derived from the Cassegrain Telescope," IRE Transactions on Antennas and Propagation, Vol. AP-9, March 1961, pp. 140-153. 